Chapter 5

\title{
Permanent Molding of Cast Irons - Present Status and Scope
}

\author{
M. S. Ramaprasad and Malur N. Srinivasan \\ Additional information is available at the end of the chapter \\ http://dx.doi.org/10.5772/50730
}

\section{Introduction}

We have only one earth and we must protect it. It is no more an option but an imperative that we adopt proactive measures to protect the earth and move towards Greener world. The official UN website lists 10 sectors for a greener planet. One of the sectors, is, Industries.

Industries drive economic growth, but they also produce pollutants and can exhaust natural resources. They also generate a lot of waste. If we do not curb the same, the planet may soon become chocked with rubbish.

Despite all the developments, foundry industry is way far from green. The situation is worse in the case of sand foundries. Sand foundries, in addition to producing hazardous air pollutants in the form of dust and fumes, also generate a lot of used sand as waste. Sand disposal is a serious problem and expensive. Our planet is threatened to become a dump yard for used foundry sand unless some feasible solutions are developed.

Sand foundries consume more energy too, thus resulting in higher fuel consumption, in turn leading to higher CO2 emissions. A Strong Energy Portfolio is needed for a strong economy of any nation.

Permanent molding (using a reusable metal mold, instead of a dispensable sand mold) offers a greener technology. While this technology is used to fairly good extent, for low temperature non-ferrous alloys, its application for the production of high temperature ferrous castings is rather limited. The technology of PM of ferrous metals was born almost a hundred years ago, but has not made much progress. Although some progress is seen in the last two decades, it is nowhere near desirable. The slow growth is vastly attributed to poor mold life. There is an urgent need to develop better mold materials. 
This paper reviews in detail, the past developments in permanent mold technology for cast iron (including some research work done by the present authors). The present status of the technology is briefly discussed. Some plans for future work are suggested.

\subsection{Permanent Molding Process (PM)}

In Permanent Molding Process the molten metal is poured repeatedly into a reusable, refractory coated, metal mold, to produce a large number of shaped castings. This is unlike all the variants of the conventional Sand Casting process (SC), which use a dispensable mold. The repeated usage of the mold is the main advantage of the PM process.

It is very essential to make the following clarifications at the outset.

- The word Permanent does not mean that the molds last forever. In fact, the useful / service life of the mold depends largely on the pouring temperature, the material of the mold and the complexity of the component being cast [1]. The other factors are: casting weight, the thermal cycle, mold preheating, mold coating, gating design, cleaning, storage \& handling, and, whether the operation is manual or automated. The end use of the casting also has a bearing (If the structural function of a casting is the only criteria, and not its appearance, a mold can be used longer before discarding) [2].

- Although, by and large, the permanent molds are metallic, graphite molds, used at times, also come under the category of Permanent Molds [2].

- The cores employed may be either metallic or made of sand. When sand cores are used, it is called a Semi-Permanent Molding ( SPM ) process.

- Permanent Molds are used in a number of variants of casting processes like Gravity Die Casting (GDC), Low Pressure Die Casting (LPDC), High Pressure Die Casting (HPDC), Centrifugal Casting (CFC), Squeeze Casting (SC) and Continuous Casting (CC).

- Throughout this paper, the terminology Permanent Molding is used to mean Gravity Die Casting only.

- Some foundrymen call it Chill Casting Process (CCP) since the metal mold cools the casting rapidly.

\subsection{Advantages of PM}

In addition to the main advantage over the sand casting process as mentioned above, the PM process offers several other distinct advantages like:

- Higher productivity (7-10 tons / man / month as against 3.5 tons / man / month in the case of sand casting process) [3], 
- Better repeatability, dimensional stability, geometric fidelity and near - net shaped castings.

- Denser castings (finer grain structure), and superior surface finish that reduces the postcasting cleaning operations. Better surface finish also renders improved static bending and fatigue properties.

- Closer dimensional tolerances and hence lower machining costs,

- Elimination of sand (less polluting) and hence no costly sand handling equipment (\& its maintenance),

- Reduced floor space and the ease of mechanization for mass production,

- Better process control due to the flexibility in design for heating and cooling of any particular location in the mold;

- Possibilities of incorporating certain design features for achieving a higher casting yield.

- The process is more energy efficient than sand casting process since the heat remains within the process loop.

\subsection{Disadvantages of PM}

There are several disadvantages in employing PM as compared to SC. The serious limitations are with regards to:

- The limitation on types of alloys that can be handled,

- Size, Shape and Section thickness of the castings,

- The batch size that can be economically handled. Since the tooling costs are relatively high, the process can be prohibitively expensive for low production quantities [2].

\subsection{Few Other Issues Concerning PM}

The flowability (fluidity) and fillability of metal in metal molds is poorer compared to sand casting process. Permeability of the mold is zero which calls for extremely carefully designed Air Venting System.

Due to the faster heat extraction, the rigidity of the metal mold (and metal cores), as also due to the thermal expansion / contraction problems associated with the metal molds (and metal cores), the stresses developed in the castings during the solidification is much higher than in the sand castings. This calls for a very careful mold and core design as well as proper casting extraction method.

Air Gap formation is one unique feature applicable to metal molds and this has a significant effect on the mode and hence the heat transfer rate through the mold. Since the structure of 
the solidifying casting partly depends upon the freezing rate, a thorough understanding of the behavior of air gap formation is very vital for satisfactory design of the mold and operating parameters. The pattern of air gap formation also affects the location of the shrinkage within the casting [4].

Unlike in the case of sand casting process, where the metal after preparation and treatment can be poured into several molds in one go, in the case of PM process the metal is often held for a while (sometimes for hours) for repeated pouring into a set of dies. Holding the metal for long has its own associated quality issues (temperature drops and fading effect of certain melt treatments).

\subsection{Where Does PM Stand Today?}

Although Permanent Mold casting ranks second to sand casting in terms of popularity, the tonnage produced by the process is only a small percentage of that made by sand casting [2].

\subsection{March Towards Green Foundries}

Recent years has witnessed some serious attempts made towards green foundry operations [5-10].

Today's Global Green Initiative has prompted manufactures, including foundrymen, worldwide, to seriously look into Environmentally Benign Manufacturing (EBM) [5]. Foundry industry is one amongst a very few others that consume a lot of energy and also produce considerable amount of dusts \& fumes, and wastes. The sector has an uphill task in going greener.

The speech presented by Gigante, as the American Foundry Society Hoyt Memorial Lecture for 2010 touches upon the issue of The Green Assault in foundries [6].

The 2002 Annual Report on Metal Casting Industry of the Future published by the US Department of Energy [7] says that as per the priorities outlined in the Metal casting Technology Roadmap of USA, $2 / 3^{\text {rd }}$ of research funding goes toward improvements in manufacturing processes, where greatest opportunities for energy saving exist. Additional research funding is going to improvements in material performance (thereby reducing scrap and increasing yield), as well as to address environmental needs such as recycling of foundry spent sand. According to this report, Metal Casting is one of the most energy intensive industries in the United States and it is very critical to the to the U.S. economy as $90 \%$ of all manufactured goods contain one or more cast metal components and that the metal castings are integral in U.S. transportation, energy, aerospace, manufacturing, and national defence. Situations are likely to be similar in most other countries.

Technikon LLC, a privately held contract research organization in California operates the Casting Emission Reduction Program (CERP), a cooperative initiative between the Department of Defence (U.S. Army) and the U.S. Council for Automotive Research (USCAR). Dur- 
ing 2004 - 2007, Technikon has published a number of reports [8-10] based on detailed studies carried out on connected topics like:

the sources of various Hazardous Air Pollutions or HAPs - both organic and inorganic (metallic), in different foundry operations[8], Monitoring Systems for HAPs [9], Energy Reduction in Foundry operations[10], the development of economically feasible permanent Mold system for high temperature alloys like iron, steel, Nickel, and Titanium[1]. The conclusions of these studies give a very good indication of the task ahead of foundry industry to become Green.

A study of the above reports give a hint that foundry industry will now be under a constant scanner and they will face never - ever - seen pressure due to stricter \& newer environmental acts that are emerging globally. Foundries will be compelled to reduce emissions of fumes and dust so as to comply with these stricter norms. Further, their operations must be improved or changed to become more and more energy efficient to reduce the fuel consumption. It appears that all the future developments in the field of foundry will be dictated more by this Green Initiative than any other factor.

\subsection{Foundry Scenario From the Above Perspective}

On a worldwide average, sand castings account for almost $80 \%$ of the castings produced. Despite advancements in the foundry technology, sand casting operation is far from Green in the following respects and hence is a serious hindrance to The March Towards A Green Planet.

- Sand casting foundries emit a lot of dust and fumes causing environmental pollution and health hazard to operators. This is in addition to the problem of heat normally involved in any foundry (Inadequacy of labor force to work in such environment has already affected the foundry sector).

- Sand costs and sand transportation costs are constantly going up [1]. Sand mining may face restrictions in future.

- Sand reclamation systems are energy intensive and expensive to operate \& maintain.

- Sand disposal is a serious problem and is expensive. Our planet is threatened to become a dump yard for used foundry sand unless some feasible solutions are developed.

- HAPs' monitoring systems are also expensive to operate and maintain [1].

- Foundries in general, and sand casting foundries in particular, may be eventually forced to move to remote areas (where infrastructure may be inadequate). Sand transportation cost may also go up as a consequence.

- As mentioned earlier, sand casting operation is less energy efficient compared to PM process.

- As per the statistics available, mold \& core making, and shot blasting operations consume almost $27 \%$ of the total energy cost in a foundry. This will be far less in the case of PM process. Even if PM process uses sand cores, the organic emissions would be relative only to the amount of core [8]. 
These above mentioned issues are prompting foundrymen worldwide to seriously consider possibility / feasiblity of converting some sand castings to equivalent PM castings. Holmgren and Naystrom [11] strongly advocate that for a Green Foundry, one must not only use the Best Available Technique (BAT), but also evaluate and create better and better techniques (through Practice - Oriented R \& D) for a good environment. One obvious approach is of course the increased utilization of Permanent Molds, which almost eliminates a sand waste stream [1]. In fact, for some castings, minor changes can permit conversion to PM castings thereby giving the above - mentioned benefits with regards to reducing HAPs, in addition to considerable cost savings [2]. The present authors firmly believe that in the very near future, such environmental issues will bring about Compelled-process-Changeovers. This will bring additional opportunity to PM process. This applies not only for non - ferrous castings but to ferrous castings as well (mainly, cast irons).

This brings us to our main topic of Permanent Molding of Cast Irons.

\subsection{Permanent Molding of Cast Irons}

The application of PM for ferrous alloys has been rather limited. The published literature on the subject is also very little. The subject is addressed only here and there in some publications, only occasionally, covering some very general aspects. It appears that a thorough understanding of the subject is somewhat lacking and that this subject has not been given its due attention. Most foundrymen raise their eyebrows in disbelief at the mention of cast iron production by PM process!!! This clearly shows that the technology has not been popularized to the extent it deserves and there is a serious lack of awareness.

However, it is well in place to mention here that there are a few publications $[12,13]$ that give an indication that PM Cast Iron castings are produced in reasonable quantities in several countries of Former Soviet Union (almost 15 \%), Eastern Europe, Germany and Japan, in a small way in USA and Canada, and a few Asian countries. Lerner [13] mentions that although the technology of PM of cast iron originated on the U.S. soil, the process has been more widely embraced overseas. According to him, in Europe, $6-8 \%$ of all iron castings are made by PM, and, that the growing use of the process is also seen in China and India. However, beyond such general information and a minimal statistics quoted here and there, no detailed information is available on this technology, both in terms of research and practice.

Considering the great potential that this technology has, particularly in the context of going Green as discussed above, there is an urgent need to work on improvements in the process. The very first step is to bring the awareness on this technology amongst the broader spectrum of foundry community. The authors of this paper are constantly working in this direction with reasonable success.

In what follows, the authors present a brief review of the work done world over, in the past - in the chronological order. They share their own findings based upon their research and practice. 


\section{Work Done So Far on The PM of Cast Iron}

- $15^{\text {th }}$ Century - Cannon balls of iron were made in two part metal molds at the end of $15^{\text {th }}$ century and a patent covering this process was taken out in Germany in 1898 [14].

- 1920s - Holly Corp cast the Ford Model “ T “ carburetor of gray iron in PM [12,15,16]. They sold the company to Eaton Corporation, Michigan, in 1930. From then onwards, the process is called by the name Eaton Process. (During that period, Forest City Foundry was the only other making substantial use of the process of cast iron PM [12,17].

- Aug.1925, Walter Anderson of USA got a patent for developing an improved permanent mold for cast iron [18]. The invention related to the design of the in-gates and air vents to enable proper filling of the metal.

- 1932 - The Ferrous Permanent Mold (FPM) Process was patented by Eaton Corporation [13].

- 1959 - The very first significant publication on Eaton Process [19] provided valuable practical information on the process - the iron poured, mold material, die operating parameters, the coatings, heat treatment, the structure \& properties of the end product and finally mold failure modes. The paper also provided some valuable information on the type of castings made by the process using a twelve - station turntable Eaton Permanent Mold Machine, with varying speeds of rotation.

- 1965 - A publication from Foseco [14], provided very useful practical information on the process parameters. In addition, the paper gave some information on mold design (gating, venting and feeding). The author also discussed the influence of the mold weight / casting weight ratio (WR), mold temperature \& pouring temperatures, mold coating, mold cooling parameters and the casting removal, on the mold life. Casting defects common to the process were also highlighted. It was clearly spelt out that in addition to the design and chemical composition of the mold, WR is also very important.

- 1966 - 1973. Although not directly a part of the present topic, it may not out of place to make a mention of few developments in other variants of PM casting of ferrous materials. Some of the experiences gained through this can possibly be made use of in the Gravity Die Casting Process also.

1. Progress made by Lamp Metals\& Components Dept., General Electric Co., Cleveland on the Pressure Die Casting (PDC) of Ferrous materials (gray iron, malleable iron, ductile iron, and various steels) using molds made of unalloyed - pressed \& sintered molybdenum [20-24].

2. Southern Research Institute, Birmingham, Alabama, USA successfully employed graphite permanent molds for gray and ductile iron castings [25]. The paper claims that the cost benefit and quality of end product of this process, as compared to sand casting process, is very attractive. This is in addition to lesser emission, better safety and lesser health hazards.

3. The successful development of pressure die casting of ferrous materials in Federal Die Casting Co., Chicago and its expansion unit in Ireland. Tungsten and molybdenum were used for the molds to overcome the temperature problems [26]. 
4. A publication from Poland [27] indicated the usage of Shaw Process for producing the permanent molds (molds for pouring both ferrous and non-ferrous alloys). Traditional methods of making the permanent molds by means of machining semi finished cast products with considerable allowances for machining are time consuming, expensive, requires specialists and special equipment. Reduction/elimination of machining of mold working surface brings about some savings in mold material, labor cost and investment cost. Considering the cost of molding materials used in Shaw Process, the ceramic slurry is used only for that part of the mold that is a direct reproduction of its working surface, which in turn corresponds to the outer surface of the final casting. This is a very useful information for implementation.

- 1967 - A book by Fisher [28] devoted a chapter on the technology of PM of cast iron. The chapter addressed the issues like cast iron composition, mold material, mold coating, die \& pouring temperatures.

- 1968 - Yet another important publication from Eaton Corp [15] provided various practical aspects of the process.

- 1968 - 1970 - Skrocki and Wallace at Case Western Reserve University did research on various aspects of PM of cast iron. They studied the effect of mold coatings, mold \& pouring temperatures, velocity and the casting section thickness on the filling ability of the metal [29]. They also made a significant contribution to the understanding of solidification behavior of cast iron at high cooling rates that are encountered in PM process [30-31]. This understanding, in turn provided very valuable information on the resulting structure and properties of the end product, under different operating conditions.

- 1970 - Chapter on Permanent Molding in Metals Hand Book, Vol.5, $8^{\text {th }}$ edition [32] gave a brief description of the process of PM of cast iron. A publication, "First Annual Summary of recent literature on PM Casting of Cast Iron " by Schoendorf [33] which appeared in the same year gave very valuable information on the subject.

- 1970 - 1973 - Ramesh [34] undertook a long-range study on various aspects of casting hyper eutectic cast iron in metal molds.

- 1972 - A publication from Zuithoff et al [35] indicated that there was a steady increase in production of cast iron permanent mold castings in the East European countries. The report also mentioned that in the then U.S.S.R increasing quantities of nodular cast iron were produced using PM process. The paper further provided some interesting statistics indicating that in the Western Europe and U.S.A. also there was a rising trend in the production of cast iron castings by PM process (in England, $2.5 \%$ of total output in 1957 and 4 \% in 1967; and in U.S.A. $1.5 \%$ in 1957 to 5\% in 1967).This clearly indicates that the growth in volume of permanent molded cast iron castings between 1920 and1967( nearly 5 decades ), has been very insignificant, more so considering the world average. This point is noteworthy and deserves detailed probing into the reasons behind.

- 1973 - The authors of the present paper published a detailed analysis of the past literature on the subject [36]. 
The analysis showed that the process of cast iron PM was still not fully exploited commercially, the progress appeared quite slow, and that there was still a vast lack of knowledge on the thermal and metallurgical aspects of permanent molded cast irons. The reasons for slow progress were attributed to the following.

a) The pouring temperatures involved are higher there by putting a higher demand on the metal for the mold.

b) Cast iron as an alloy, though very easy to cast, it is very difficult to understand in terms of the behavior. The structure and properties of cast iron not only depend upon the Chemical Composition, Melt Treatment and Heat Treatment but also vastly on the cooling rates during solidification. Cast iron is a section sensitive alloy. The matrix structure and the graphite morphology could vary from one extreme to the other. Further, It is possible for the same casting to have several combinations of graphite forms and matrix, at different locations, which means that the properties such as strength, ductility, machinabilty, wear resistance, damping capacity, and others could be subject to variation over rather wide limits. Since these properties are a consequence of the structure, which in turn is related to solidification (cooling rates), it was felt essential to generate knowledge on these aspects of PM of cast iron.

Considering this gap in knowledge, the present authors, then at the Indian Institute of Science, initiated a 3 year long research project. The parameters studied included the size and shape factor of the casting, composition of the metal, the mold \& pouring temperature, mold wall thickness, the coating material \& thickness, and the melt treatment. The effect of these parameters on the solidification, structure of graphite \& matrix and strength \& hardness were studied in great depth.

The magnitudes of the several process variables for the above research project were so chosen after a careful analysis of the earlier literature cited above, as to conform as closely as possible, with those employed by the previous investigators, as well as in industrial practice.

The main data drawn from the earlier literature are summarized in Table 1. All the relevant details regarding the various experimental conditions employed in this research project are set out in Table 2 and 3.

Out of the above study, large amount of valuable data was generated on the effect of these parameters on the air gap formation time, solidification time, solidification rate, the mold temperature distribution, the heat extraction rate, the resulting microstructure, tensile and hardness properties. The microstructures were studied not only with optical microscope but also with Scanning Electron Microscope (SEM). The SEM studies revealed a lot more information. In addition to understanding the matrix and the graphite structure as separate entities, it was possible to understand the pattern of the interface between the matrix and the graphite and how smooth or otherwise the graphite - matrix interface is. The type of this interface appeared to have a strong influence on the strength properties. With slower solidification, although the graphite is coarser, the strength was higher presumably due to smoother interface that is likely to reduce the stress concentration. 
The findings of the above research have already been reported in several publications by the authors [37-42].

Since most of the data and the analysis of the above research have already been published, all those are not covered at length in this paper. Only a few important findings are presented in brief. Very large amount of data has been generated on the thermal behavior of the molds. It must be appreciated that this research was conducted in 1974-75, almost 37 year back. With the present day advancement in the various computer simulation techniques, one can generate these data fairly accurately. Hence, for these thermal aspects, only some typical graphical representations and a summary are given. However, many SEM microstructures (not exhibited in the earlier publications) are presented for the benefit of the readers, since the microstructure part cannot be so easily / accurately predicted by the use of a software.

\begin{tabular}{|c|c|c|}
\hline & $\begin{array}{l}\text { Material of cast } \\
\text { iron poured }\end{array}$ & $\begin{array}{l}\text { Hypereutectic cast irons. (Carbon Equivalent, C.E in the range of } 4.20 \text { to } 4.60 \text { ) are invariably used } \\
\text { for permanent molding }[3,14-17,19,28-35]\end{array}$ \\
\hline 2 & Mold $\mathrm{N}$ & $\begin{array}{l}\text { Cast Iron }[3,14-16,19,28-32,35] \text {. In fact most recommend a cast iron of composition same as the } \\
\text { alloy cast }[15,16,19,28,32] \text {.One recommends special alloy cast iron and Ductile Iron [14] for } \\
\text { achieving better life. }\end{array}$ \\
\hline 3 & Mold Coating & $\begin{array}{l}\text { Most investigators recommend a primary coating consisting of a mixture of China Clay, sodium } \\
\text { silicate and water, with a secondary coating of Acetylene Soot }[14-16,19,28-34] \text {. }\end{array}$ \\
\hline 4 & $\begin{array}{l}\text { Mold } \\
\text { Temperature }\end{array}$ & $\begin{array}{l}\text { Most recommend a temperature range of } 150-250^{\circ} \mathrm{C}[14-16,19,35] . \text { However some recommend } \\
\text { slightly higher temperature of upto } 350^{\circ} \mathrm{C}[3,32 .]\end{array}$ \\
\hline 5 & $\begin{array}{l}\text { Pouring } \\
\text { Temperature }\end{array}$ & Most recommend $1250-1350^{\circ} \mathrm{C}[14,32]$, while a few recommend upto $1400^{\circ} \mathrm{C}[3,17]$ \\
\hline 6 & $\begin{array}{l}\text { Mold wall } \\
\text { Thickness }\end{array}$ & $\begin{array}{l}\text { The normally employed mold wall thickness is } 12.50 \text { to } 31.00 \mathrm{~mm} \text { and the widely used Volume } \\
\text { Ratio (Volume Of the Mold / Volume of the Casting) is about } 5.00 \text { [19]. }\end{array}$ \\
\hline 7 & $\begin{array}{l}\text { Inoculation of } \\
\text { the metal }\end{array}$ & Invariably all the melts are inoculated before pouring into the mold. \\
\hline 8 & $\begin{array}{l}\text { Heat Treatment } \\
\text { of Castings }\end{array}$ & $\begin{array}{l}\text { Normally castings are given annealing treatment (heat uniformly and rapidly to } 860^{\circ} \mathrm{C} \text {, hold } \\
\text { sufficiently long to secure equilibrium between Austenite, Cementite and Graphite (normally } \\
\text { about } 75 \mathrm{~min} \text {. for castings not exceeding } 25 \mathrm{~mm} \text { wall thickness), cool slowly to ensure } \\
\text { breakdown of Cementite to Ferrite and Graphite - say at the rate of } 3^{\circ} \text { per min., between } 860^{\circ} \mathrm{C} \\
\text { and } 600^{\circ} \mathrm{C} \text { ) }[14,15,32] \text {. Annealing results in uniformity in hardness and grain structure that gives } \\
\text { many machining advantages like machining with greater feeds and speeds and longer tool life. } \\
\text { Normally, it is difficult to retain a sharp corner or a smooth thread during machining of } \\
\text { annealed gray cast iron due to the pullout of coarse graphite flakes. Such problems are not } \\
\text { faced in PM cast iron castings owing to very finely dispersed under cooled graphite structure. }\end{array}$ \\
\hline
\end{tabular}

Table 1. Process Variables - Data from past literature. 


\begin{tabular}{|c|c|c|}
\hline 1 & Alloys Poured & $\% \mathrm{C}-3: 45, \% \mathrm{Mn}-0.6, \% \mathrm{P}-0.27, \% \mathrm{~S}-0.09$ and $\% \mathrm{Si}-$ (a) $2.42 *$, (b) 3.00, (c) 3.62 * \\
\hline 2 & Mold Material & $\% C-3.5, \% \mathrm{Si}-3.2, \% \mathrm{Mn}-0.55, \% \mathrm{P}-0.36, \% \mathrm{~S}-0.042$. \\
\hline \multirow{2}{*}{3} & \multirow{2}{*}{ Mold Coatings } & a) Primary coat: China clay : Sodium Silicate : Water ( $4: 1: 20$ by weight)- $0.2 \mathrm{~mm}$ thick. \\
\hline & & b) Secondary coat : Acetylene soot- $0.1 \mathrm{~mm}$ thick. \\
\hline \multirow[b]{2}{*}{4} & \multirow[b]{2}{*}{ Test Castings** } & a) Cylinders: $150 \mathrm{~mm}$ heights. Cylinder dia ( $D_{c}, \mathrm{~mm}$ ) -- 37.5, 62.5, 87.5 and $112.5^{* *}$. \\
\hline & & $\begin{array}{l}\text { b) Plates: } 150 \mathrm{~mm} \text { width } \times 125 \mathrm{~mm} \text { height. Plate thickness }\left(\mathrm{t}_{\mathrm{p}}, \mathrm{mm}\right)-12.5,18.75,25.00 \\
\text { and } 31.25 .\end{array}$ \\
\hline 5 & Test Molds** & $\begin{array}{l}\text { Mold Wall thickness(MWT),mm of plate \& cylindrical molds-12.5, 18.75, } 25.00 \text { and } \\
31.25 .\end{array}$ \\
\hline 6 & $\begin{array}{l}\text { Mold Temperature, } \\
\left(\mathrm{M} . \mathrm{T}^{\circ} \mathrm{C}\right) \text { : }\end{array}$ & $150,200,250$ (300 and 350 in a few cases only) \\
\hline 7 & $\begin{array}{l}\text { Pouring Temperature, } \\
\left(\text { P.T, }{ }^{\circ} \mathrm{C}\right) \text { : }\end{array}$ & 1250,1300 and 1350 \\
\hline
\end{tabular}

Table 2. Process variables employed in the Research Project.

\begin{tabular}{|c|c|c|c|c|c|c|c|}
\hline Batch No. & 1 & 2 & 3 & 4 & 5 & 6 & 7 \\
\hline$\% \mathrm{Si}$ & 3.00 & 3.00 & 3.00 & 3.00 & 3.00 & 2.42 & 3.62 \\
\hline M.T. ${ }^{\circ} \mathrm{C}$ & 250 & 200 & 150 & 150 & 150 & 150 & 150 \\
\hline P.T. ${ }^{\circ} \mathrm{C}$ & 1350 & 1350 & 1350 & 1300 & 1250 & 1250 & 1250 \\
\hline \multicolumn{8}{|c|}{$\begin{array}{l}\text { Notes: * \% Si of } 2.42 \text { and } 3.62 \text { were used only for limited } \\
\text { combinations as shown in Table } 2 .\end{array}$} \\
\hline \multicolumn{8}{|c|}{$\begin{array}{l}{ }^{* *} \text { Combination of Cylinder of dia. } 112.5 \mathrm{~mm} \text { and test mold wall } \\
\text { thickness of } 12.5 \mathrm{~mm} \text { was not poured since the Volume ratio VR } \\
\text { (volume of mold / volume casting) is too low. }\end{array}$} \\
\hline
\end{tabular}

Table 3. Combination of \% Si, M.T, P.T. for different experiments.

\section{A) Findings on Solidification, Structure and Properties of the Castings a) Solidification time}

The plots of the solidification time of test castings ( $\mathrm{T}$, sec. ) against the corresponding volume to surface area ratio ( $\mathrm{V} / \mathrm{SA}$ ) indicated that there exists a relationship of the form $\mathrm{T}=\mathrm{K}$ $(\mathrm{V} / \mathrm{SA})^{\mathrm{n}}$ ( where $\mathrm{K}$ is a constant ) as in [42] when the casting size alone is varied. The value of 
$\mathrm{n}$ is constant for a given casting shape, being 1.8 for plates and 1.6 for cylinders, irrespective of the mold wall thickness, mold temperature, pouring temperature and the silicon level. The value of $\mathrm{K}$, however, increased with increase in initial mold and pouring temperatures and with decrease in mold wall thickness. Variations in the silicon level did not change the value of $\mathrm{K}$. it is very well known that similar equation holds good in the case sand castings the value of $n$ being 2 , irrespective of shape.

\section{b) Microstructure of castings}

The relationships between the type of graphite and the solidification time, \& the type of matrix and the solidification time are shown in Fig. 1 [42]. If solidification time is reckoned as a measure of the cooling rate of the casting, then it is evident from this figure that the type of graphite changes from under cooled type to flake type as the cooling rate is progressively decreased from a high value (Figs.2-3 and 4-6 and Table. 4).

In addition, the matrix changes from predominantly ferritic to a mixture of ferrite and pearlite, and again to predominantly ferritic. At very high cooling rates however, some pearlite is associated with ferrite (Fig. 1).

The observation of undercooled graphite at the surface in all castings but for those cooled very slowly, and the presence of flake graphite in gradually increased quantities towards the centre in larger castings in the present series of investigation, is in well in keeping with the trend noted above.

The matrix also changes in a predictable manner from the surface to the centre on the basis of the above consideration. Thus the microstructures of these gray cast iron castings can be predicted with confidence on the basis of heat conduction considerations. It is interesting to note that the experimental results of Skrocki and Wallace [30] are in accordance with this in respect of castings poured into molds preheated to different temperatures.

There appear to be ramifications in a given type of graphite when the structure is observed by scanning electron microscopy. However changes within a given type of graphite (undercooled or flake) also occur in a predictable manner on the basis of heat conduction considerations. Thus, as the cooling rate is progressively decreased from a high value, heavily branched undercooled graphite (Fig.7-10, 17-18) changes to rounded undercooled graphite (Fig.13-14, 33). Further reduction in cooling rate results in the appearance of flake graphite with a moderate degree of branching (Fig.15-16, 19-24,27-28,38) and at very low cooling rates coarse flake graphite (Fig.25-26, 29-30, 34-36) and some with surface protuberances (Fig. 37) is observed in the microstructure.

The SEM structures showed that in fact the graphite formed shows variety of interesting patterns like branching, curling, twisting, bending, folding, coarse graphite, smooth graphite, graphite with surface protuberances, etc., under various operating conditions. This is possibly a subject in itself, with a vast scope for further investigation. To give an idea to the readers on this aspect, several SEM pictures are presented. Those who are practicing PM of cast iron may be able to relate some of these features to their own observations, and throw some light. 
The matrix changes observed in the castings led to the postulation that diffusion distance, rate of diffusion of carbon, and surface area offered for the diffusion of carbon are all important considerations in determining the type of matrix present in a permanent mold gray cast iron casting.

\section{c) Eutectic Cell count:}

Plots of eutectic cell count values at the centre of the casting vs. solidification time show appreciable scatter especially at low solidification times [38]. It is nevertheless evident that the eutectic cell count decreases with decrease in cooling rate of the casting.

\section{d) Tensile Strength And Hardness:}

Fig. 39 shows that the tensile strength gradually decreases with increase in solidification time until about 180 seconds and the decrease thereafter is much less marked. As seen in Fig. 1 castings with solidification times longer than 180 s have a predominantly ferritic matrix associated with flake graphite at their centre. It is therefore evident that with this type of structure the tensile strength is not appreciably reduced despite the coarsening of the graphite as well as the matrix. One factor which could be of importance in leading to such behavior may be the smoothening of the leading edge of graphite which could be responsible for reduced notch sensitivity. Figure 40 shows the effect of variation of $\% \mathrm{Si}$ on the tensile strength.

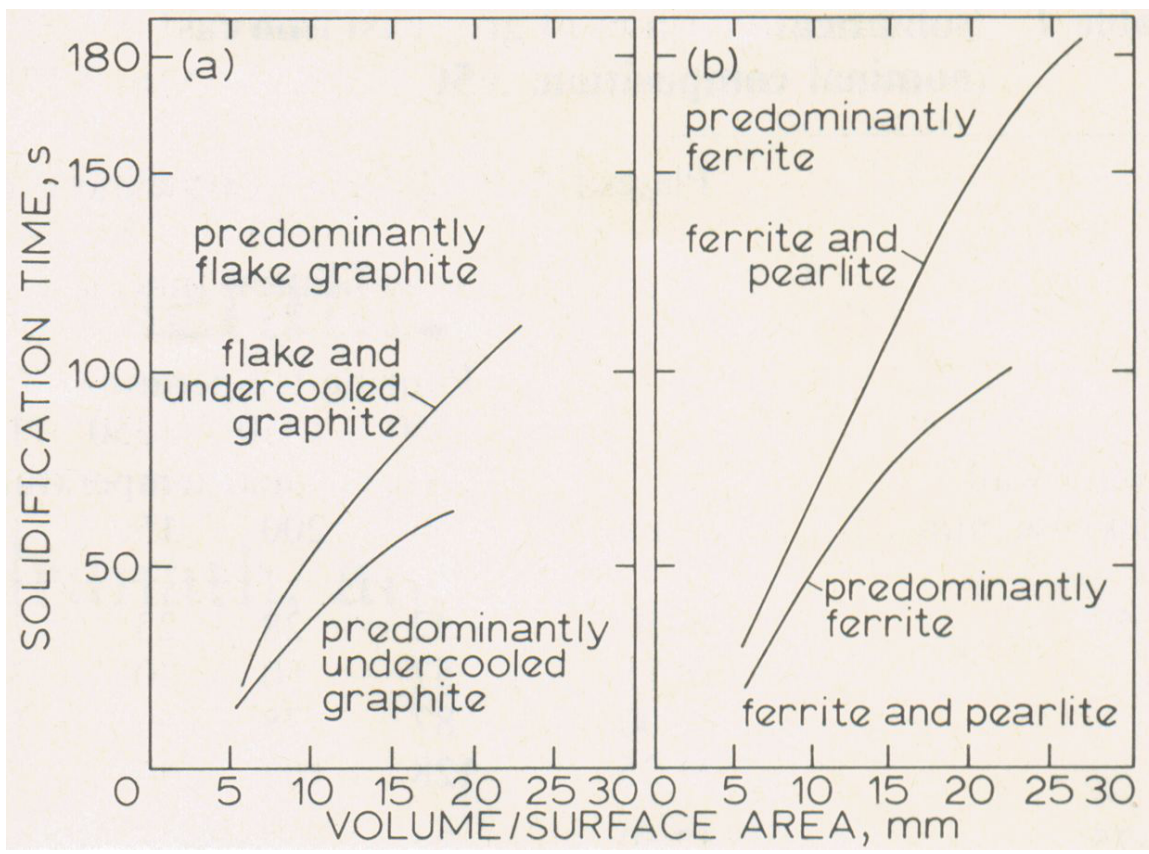

Figure 1. Variation in the graphite and matrix structure in gray cast iron [42]. 


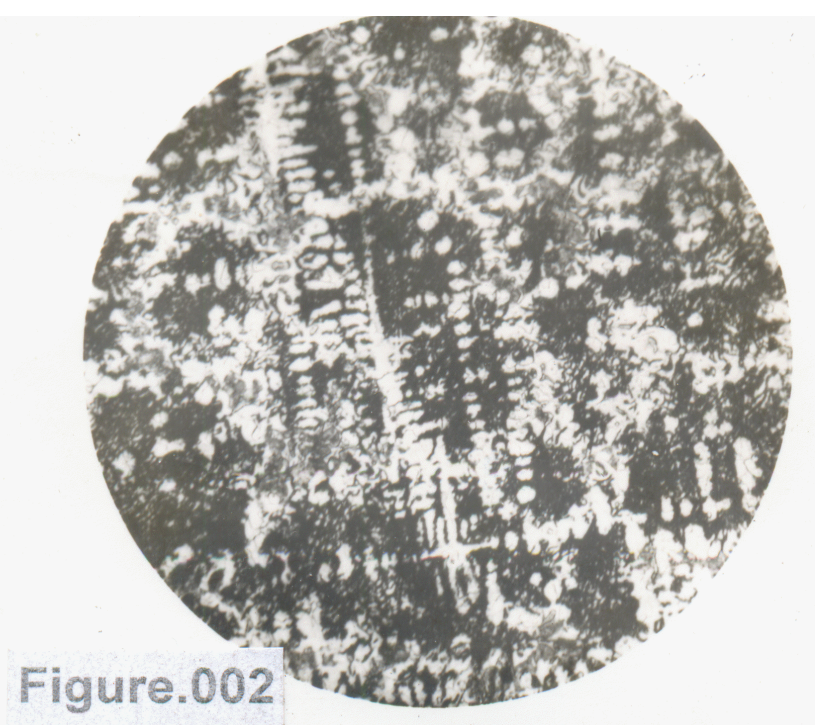

Figure 2.

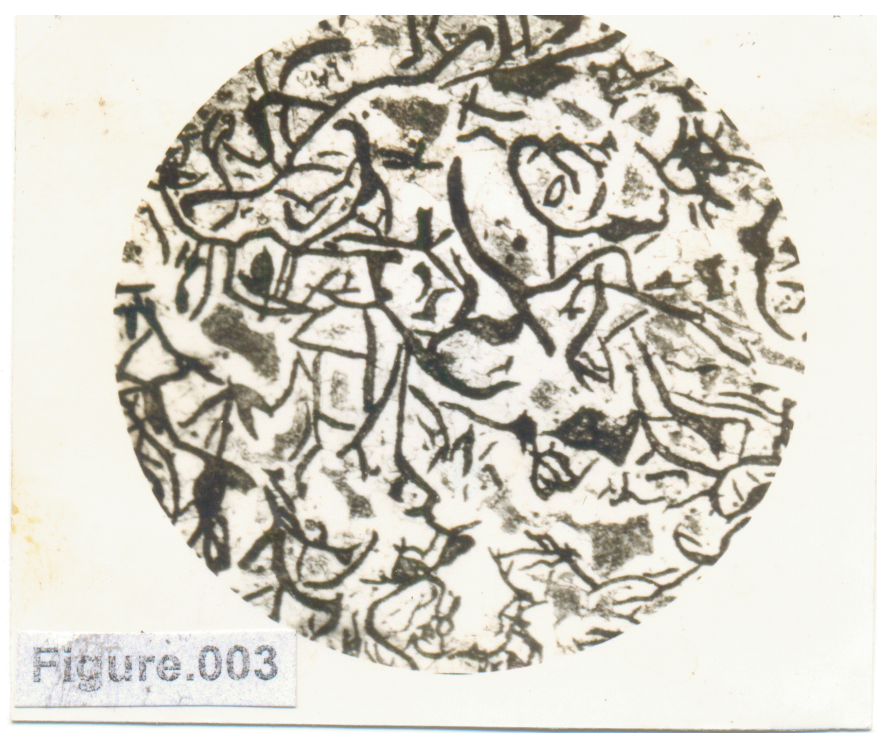

Figure 3. 


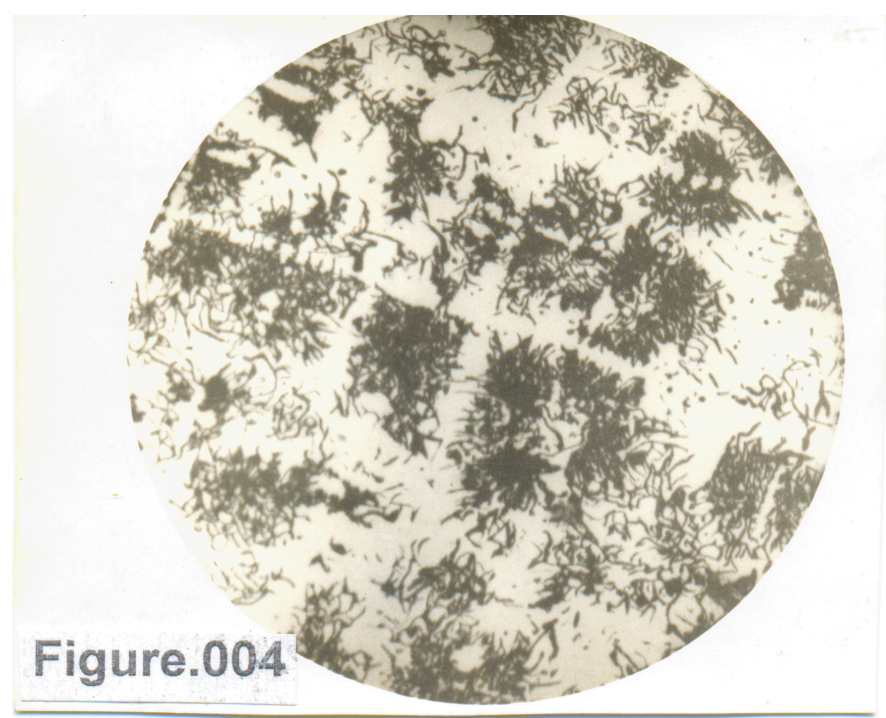

Figure 4.

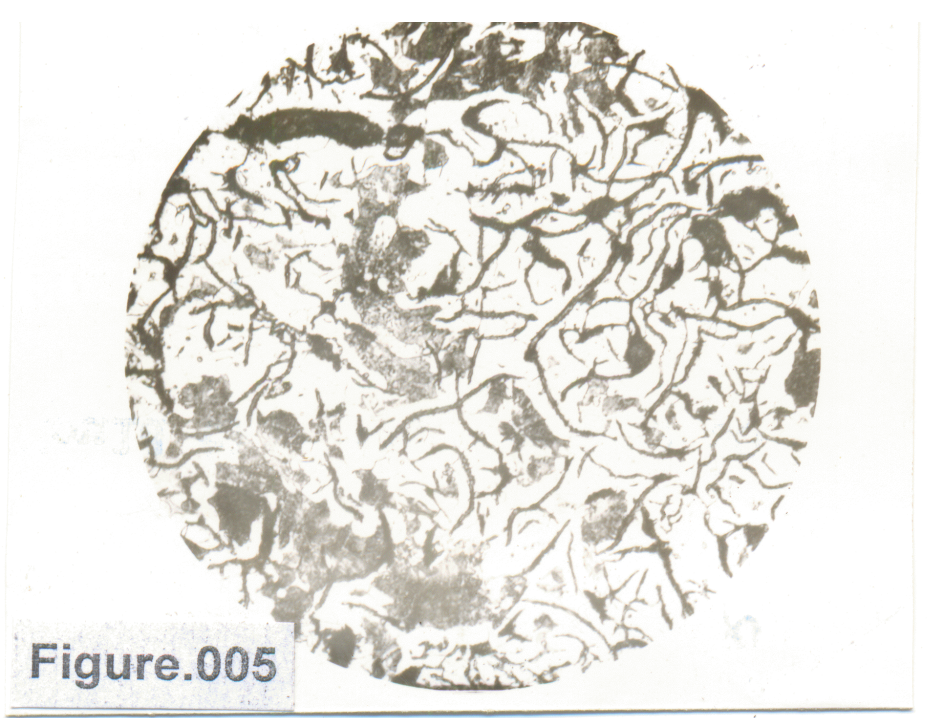

Figure 5. 


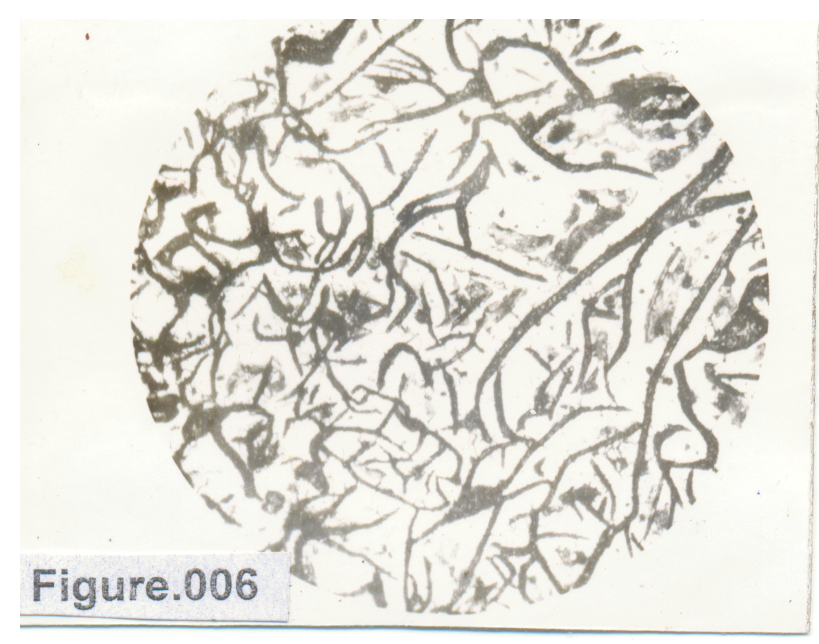

Figure 6.

Further it can be seen from Fig. 1 that castings with solidification times less than 180 sec. may have a variety of graphite - matrix combinations. Since the tensile strength falls continuously with increase in solidification time in this range (Fig. 39) it is to be surmised that factors tending to increase the notch sensitivity such as the coarseness of graphite of a given type, increased pearlite spacing, and coarseness of ferrite override the beneficial effect of the smoothening of the leading edge of a given type of graphite as the solidification time is increased in this range. Fig. 40 shows the effect of \% Si on tensile strength. Lower the \% Si, higher is the strength, in the range studied.

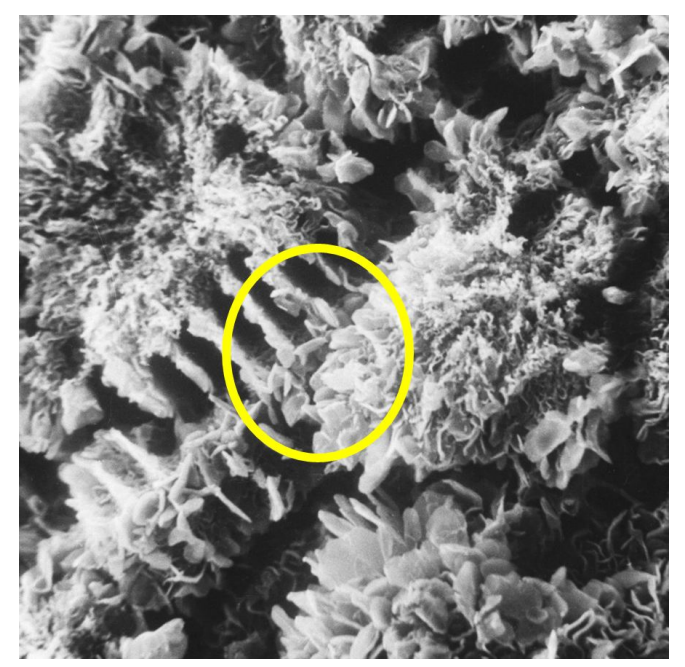

Figure 7. 


\begin{tabular}{|c|c|c|c|c|c|c|c|c|}
\hline Figure. & Shape & Size & MWT & M.T ${ }^{\circ} \mathrm{C}$ & P.T ${ }^{\circ} \mathrm{C}$ & $\% \mathrm{Si}$ & Location & Magnification \\
\hline 2 & Plate & 12.50 & 31.25 & 1350 & 150 & 3.00 & Surface & 100 \\
\hline 3 & Cylinder & 87.50 & 31.25 & 1350 & 250 & 3.00 & Centre & 100 \\
\hline 4 & Cylinder & 87.50 & 12.50 & 1350 & 300 & 3.00 & Surface & 100 \\
\hline 5 & & & & & & & Intermediate & 100 \\
\hline 6 & & & & & & & Centre & 100 \\
\hline 7 & Plate & 12.50 & 31.25 & 150 & 1250 & 3.62 & Surface & 420 \\
\hline 8 & & & & & & & & 2100 \\
\hline 9 & Plate & 12.50 & 31.25 & 150 & 1350 & 3.00 & Surface & 420 \\
\hline 10 & & & & & & & & 2100 \\
\hline 11 & Plate & 12.50 & 31.25 & 150 & 1250 & 3.62 & Surface & 420 \\
\hline 12 & & & & & & & & 2100 \\
\hline 13 & Cylinder & 62.50 & 31.25 & 250 & 1350 & 3.00 & Surface & 420 \\
\hline 14 & & & & & & & & 2100 \\
\hline 15 & Cylinder & 87.50 & 12.50 & 250 & 1350 & 3.00 & Intermediate & 420 \\
\hline 16 & & & & & & & & 2100 \\
\hline 17 & Cylinder & 87.50 & 12.50 & 150 & 1250 & 3.00 & Surface & 420 \\
\hline 18 & & & & & & & & 2100 \\
\hline 19 & Cylinder & 87.50 & 12.50 & 150 & 1250 & 3.62 & Centre & 420 \\
\hline 20 & & & & & & & & 2100 \\
\hline 21 & Plate & 12.50 & 31.25 & 150 & 1250 & 3.62 & Centre & 420 \\
\hline 22 & & & & & & & & 2100 \\
\hline 23 & Cylinder & 87.50 & 12.50 & 350 & 1350 & 3.00 & Surface & 420 \\
\hline 24 & & & & & & & & 2100 \\
\hline 25 & Plate & 31.25 & 12.50 & 150 & 1250 & 3.62 & Centre & 420 \\
\hline 26 & & & & & & & & 2100 \\
\hline 27 & Cylinder & 62.50 & 18.75 & 250 & 1350 & 3.00 & Centre & 420 \\
\hline 28 & & & & & & & & 2100 \\
\hline 29 & Cylinder & 62.50 & 31.25 & 250 & 1350 & 3.00 & Centre & 420 \\
\hline 30 & & & & & & & & 2100 \\
\hline 31 & Plate & 12.5 & 25.00 & 150 & 1350 & 3.00 & Surface & 2100 \\
\hline 32 & Plate & 12.50 & 31.25 & 150 & 1250 & 3.62 & Centre & 420 \\
\hline 33 & Cylinder & 112.50 & 31.25 & 250 & 1350 & 3.00 & Surface & 2100 \\
\hline 34 & Cylinder & 112.50 & 31.25 & 250 & 1350 & 3.00 & Centre & 2100 \\
\hline 35 & Cylinder & 87.50 & 12.50 & 150 & 1250 & 3.00 & Centre & 2100 \\
\hline 36 & Cylinder & 87.50 & 12.50 & 250 & 1350 & 3.00 & Centre & 2100 \\
\hline 37 & Cylinder & 87.50 & 12.50 & 350 & 1350 & 3.00 & Centre & 2100 \\
\hline 38 & Cylinder & 87.50 & 12.50 & 150 & 1350 & 2.42 & Centre & 2100 \\
\hline
\end{tabular}

Table 4. Values of Casting Parameters applicable to microstructures (both Optical and SEM). 


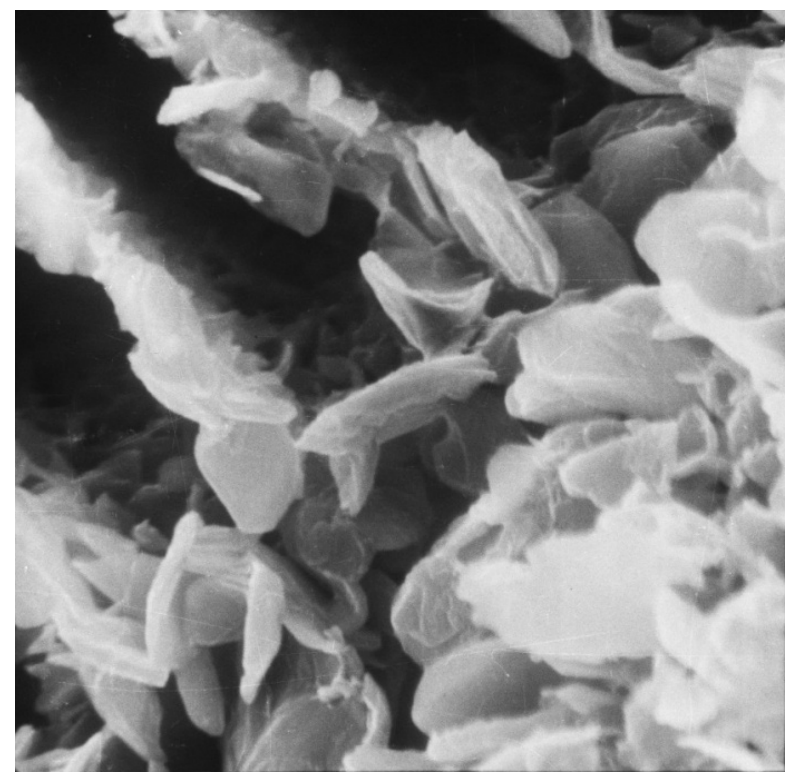

Figure 8.

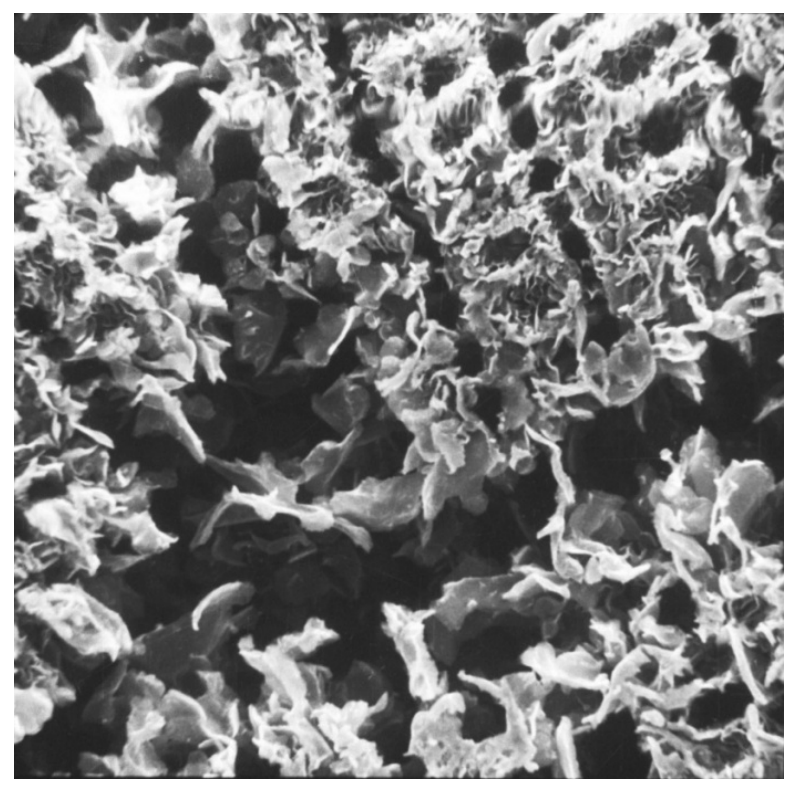

Figure 9. 


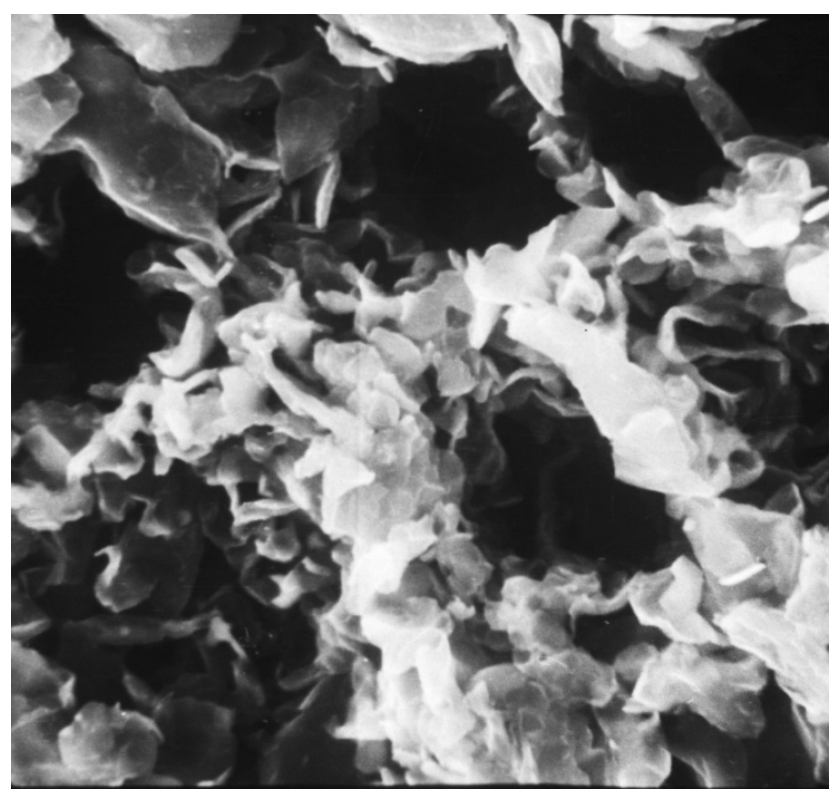

Figure 10.

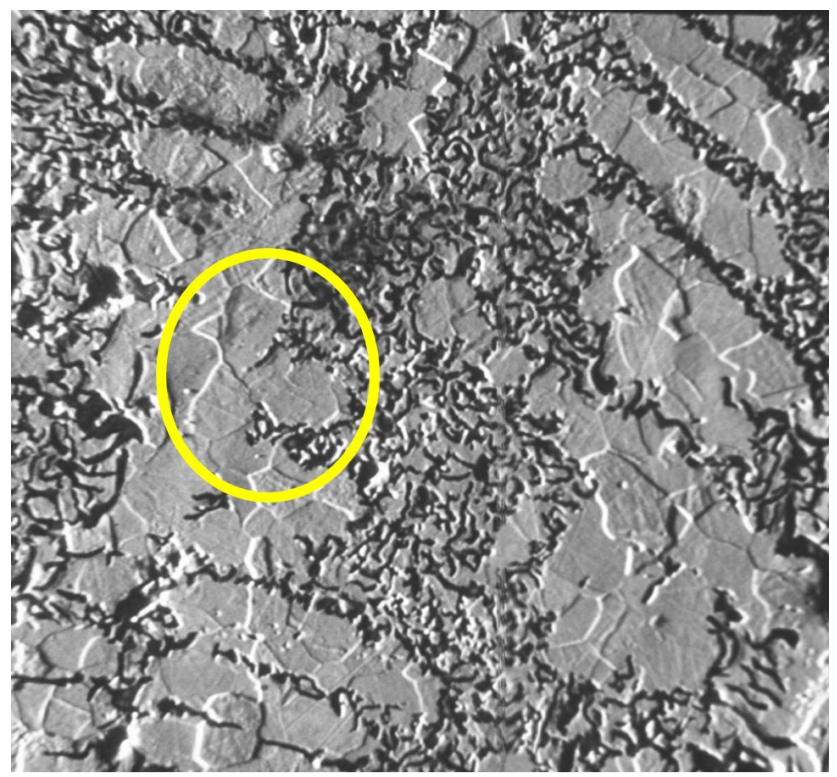

Figure 11. 


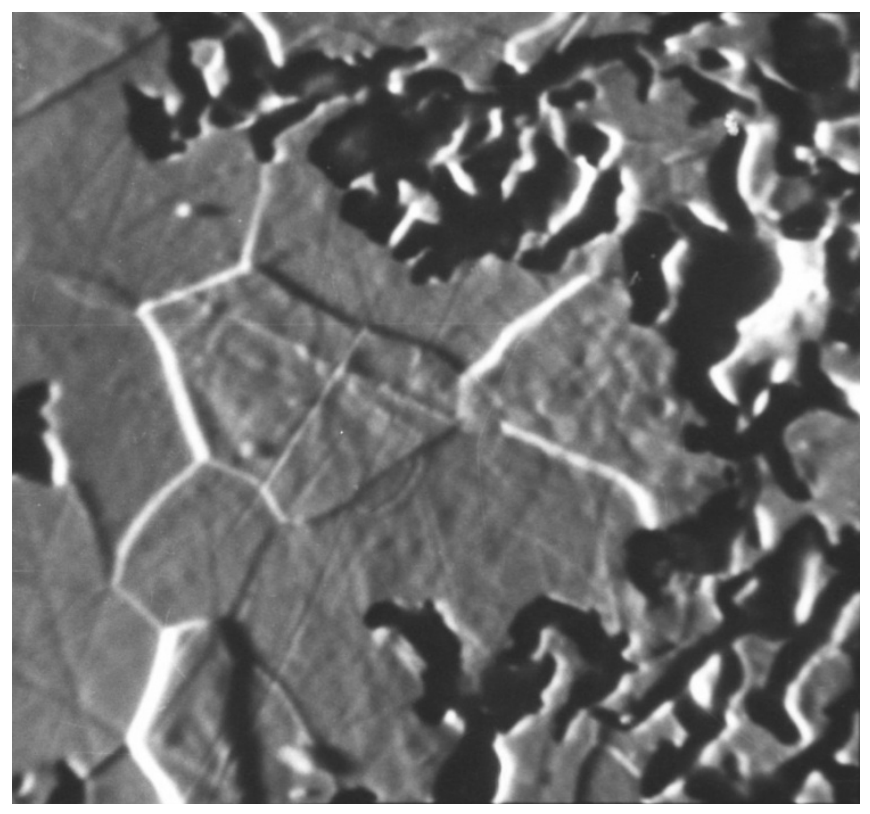

Figure 12.

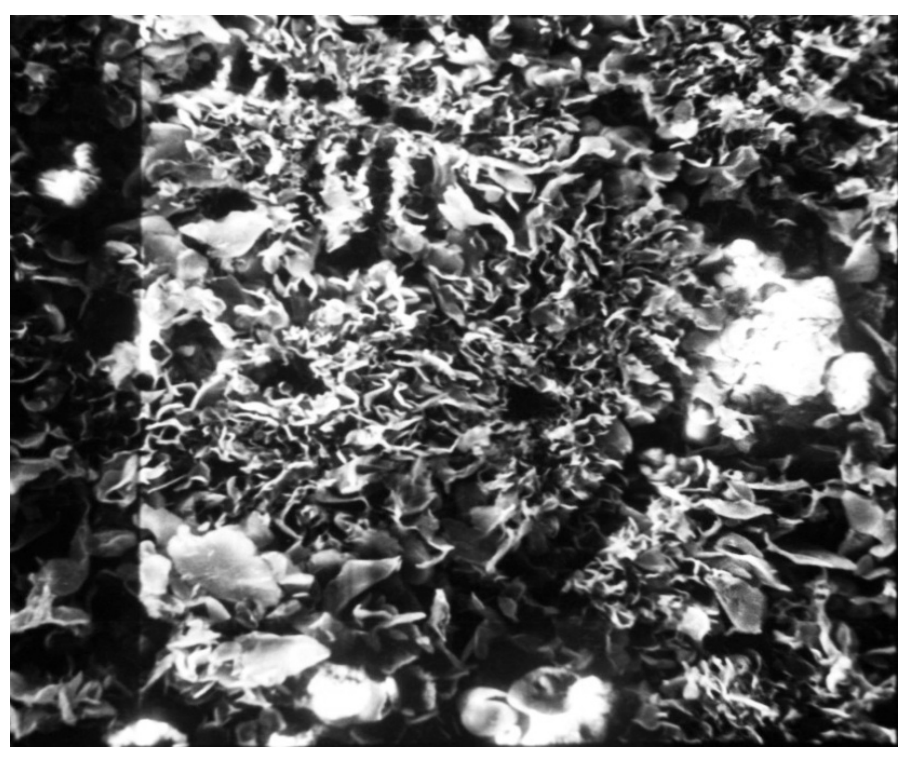

Figure 13. 


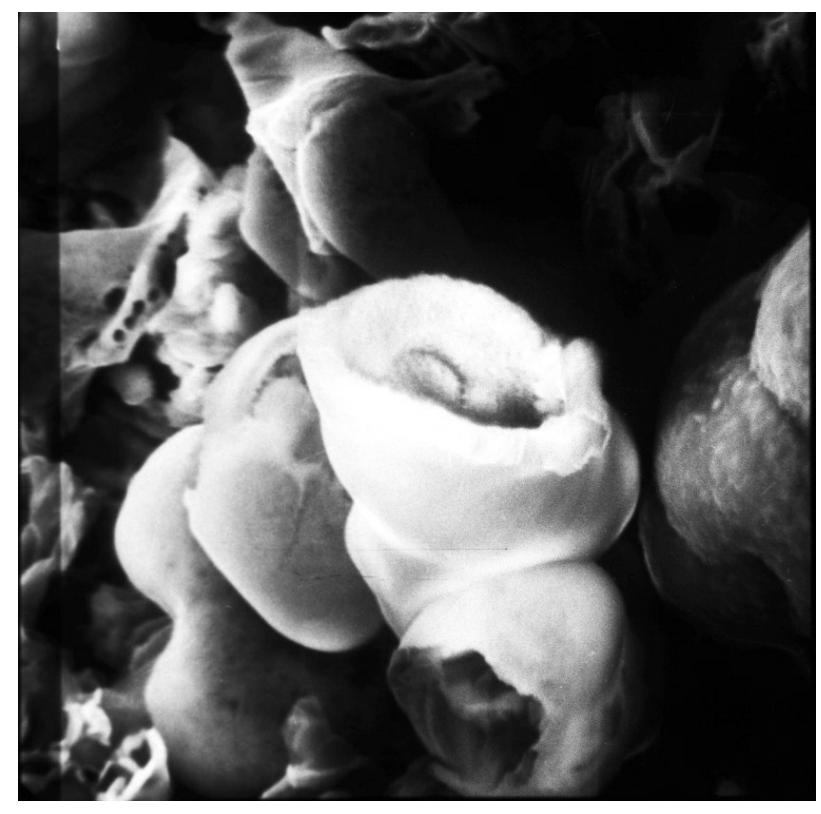

Figure 14.

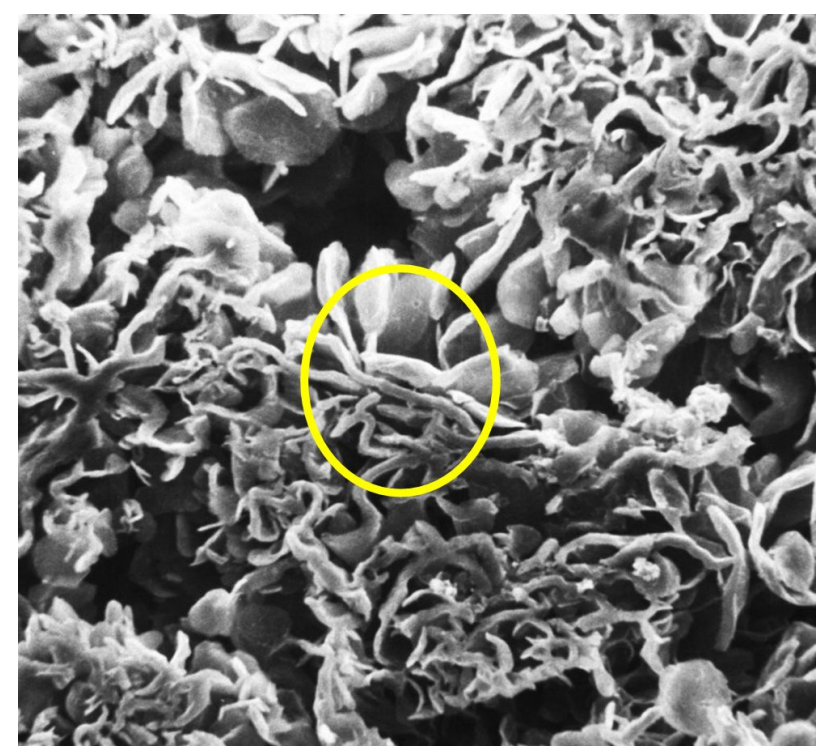

Figure 15. 


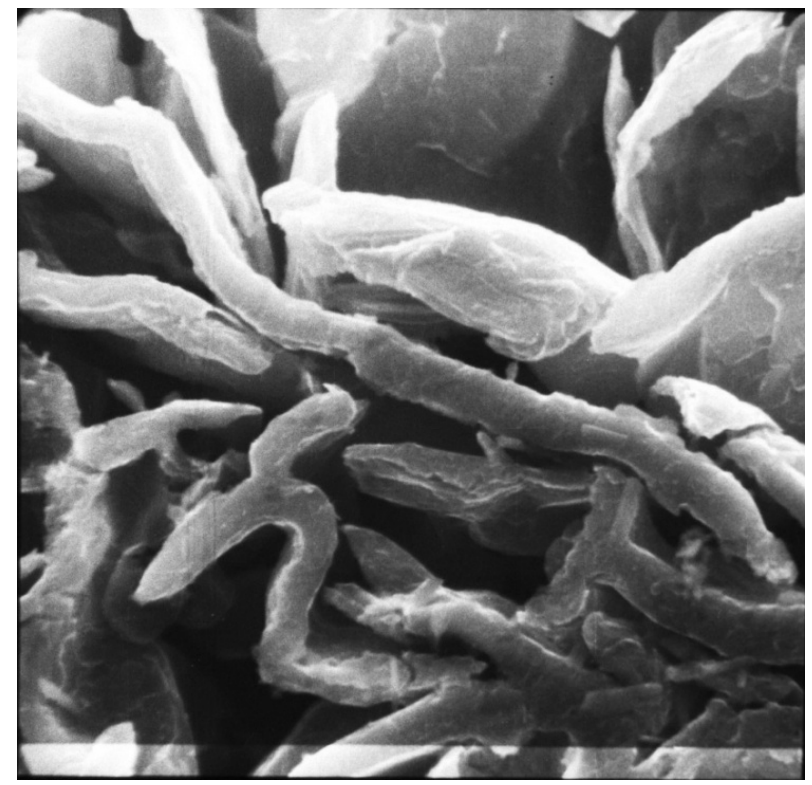

Figure 16.

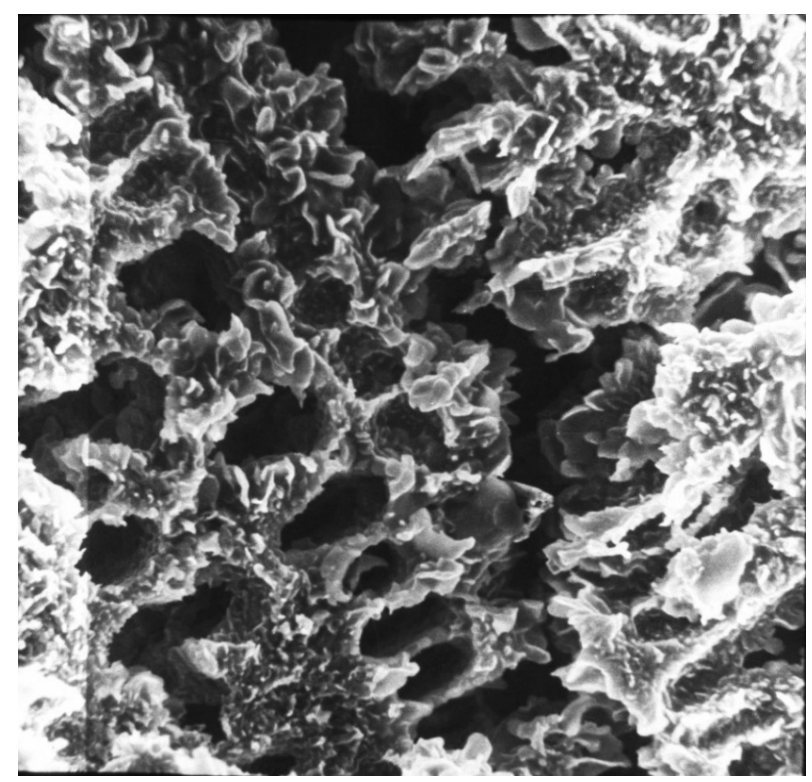

Figure 17. 


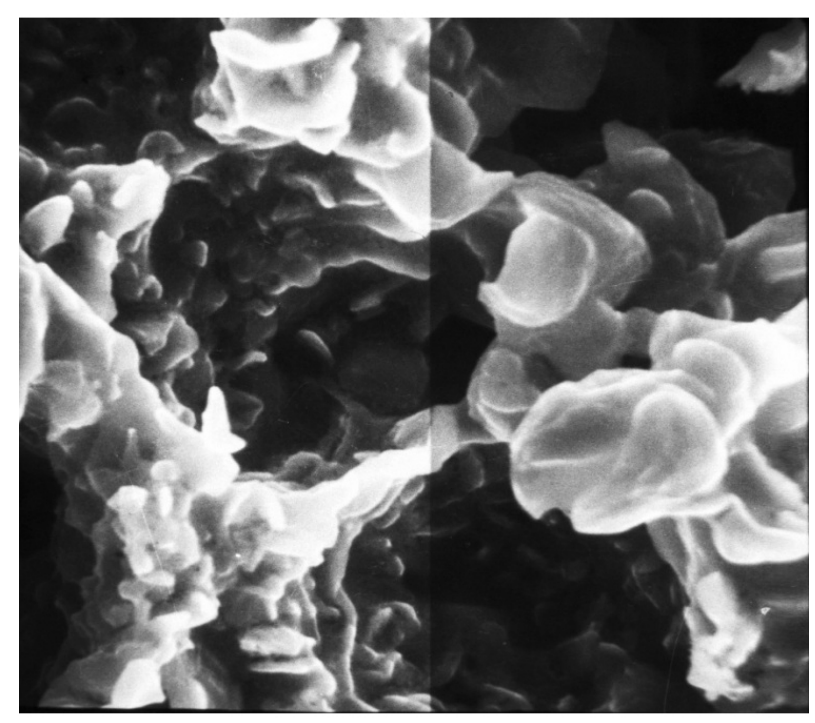

Figure 18.

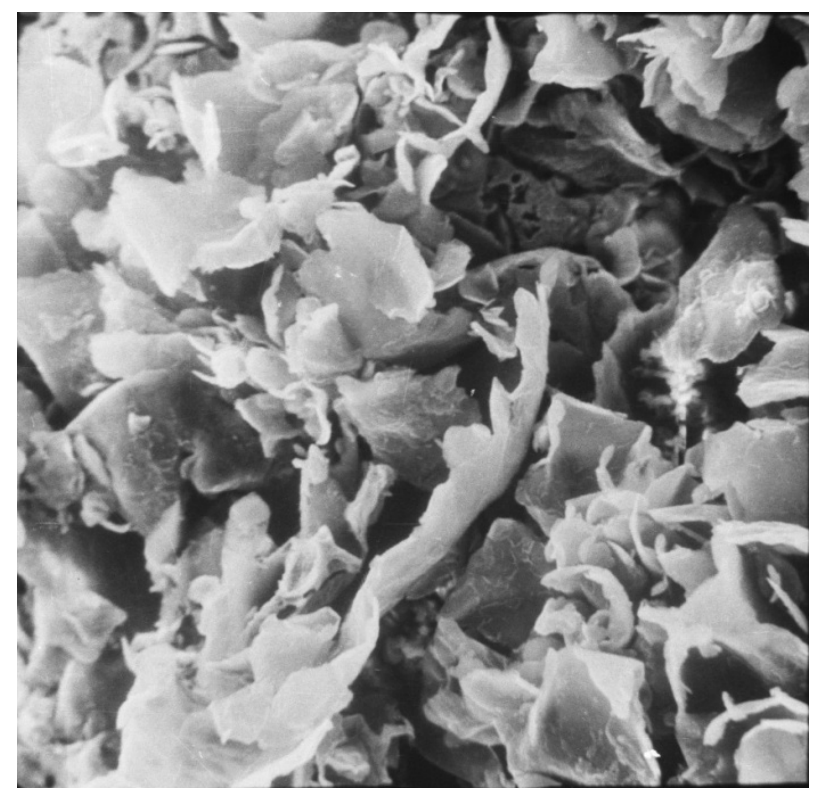

Figure 19. 


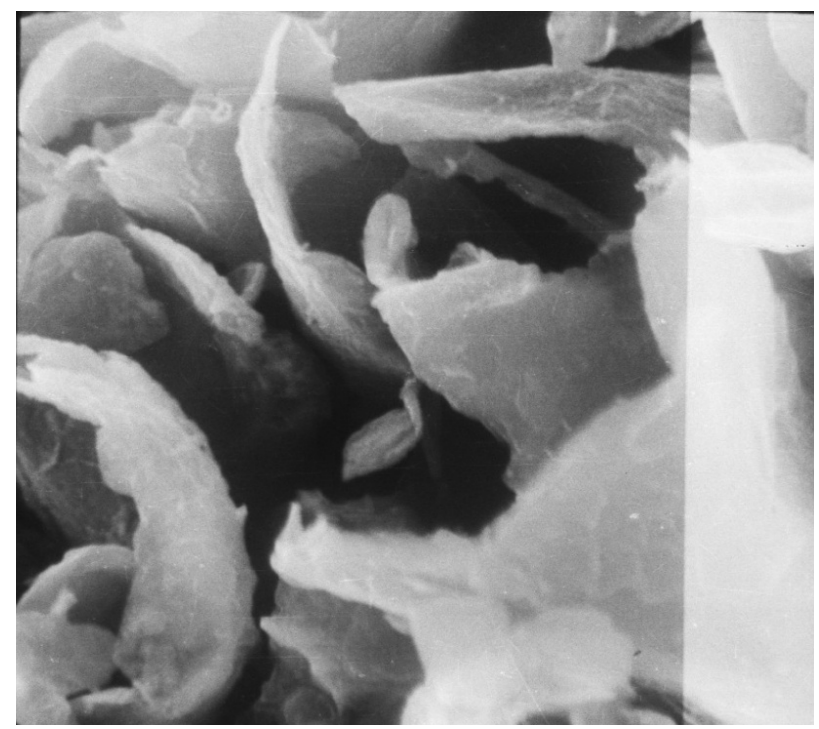

Figure 20.

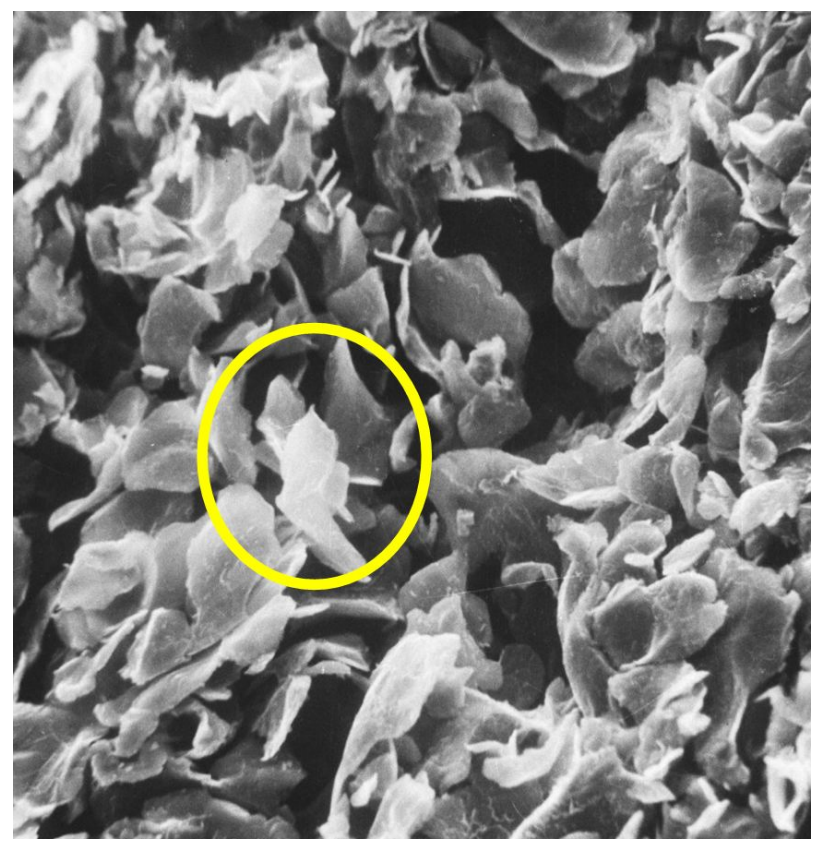

Figure 21. 


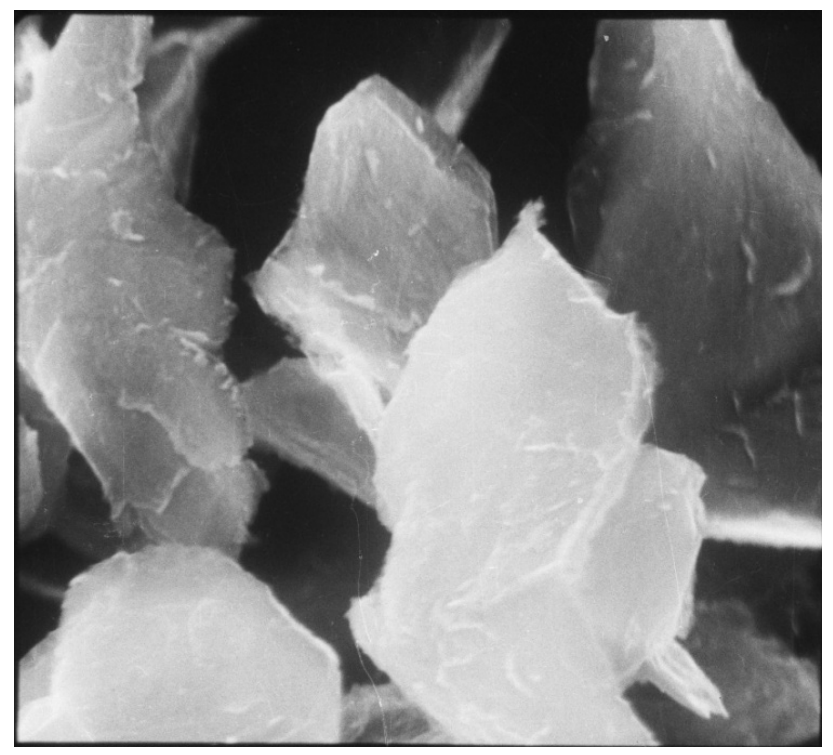

Figure 22.

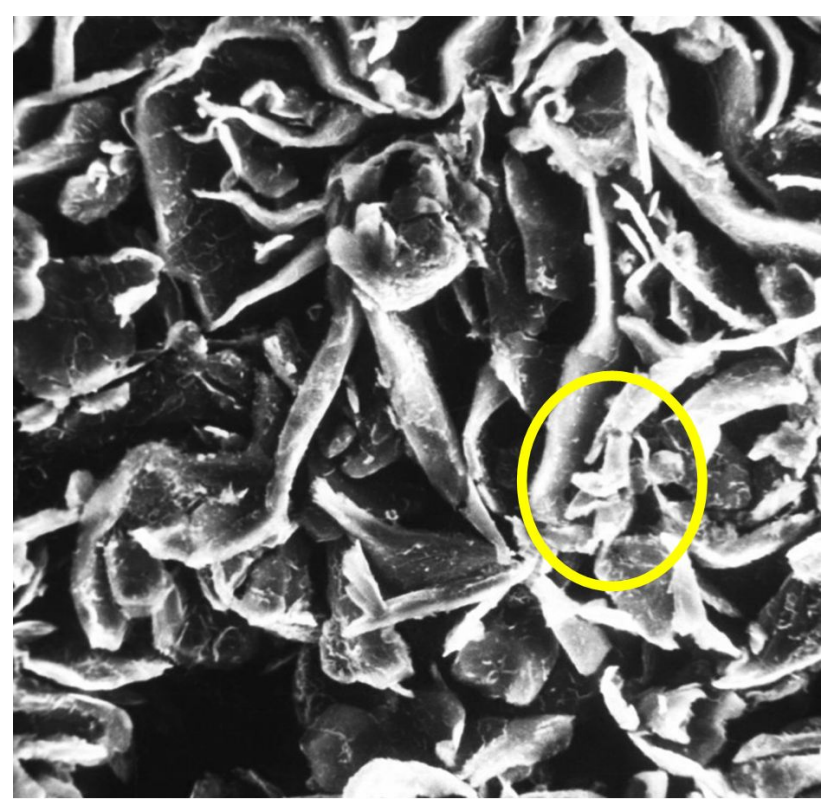

Figure 23. 


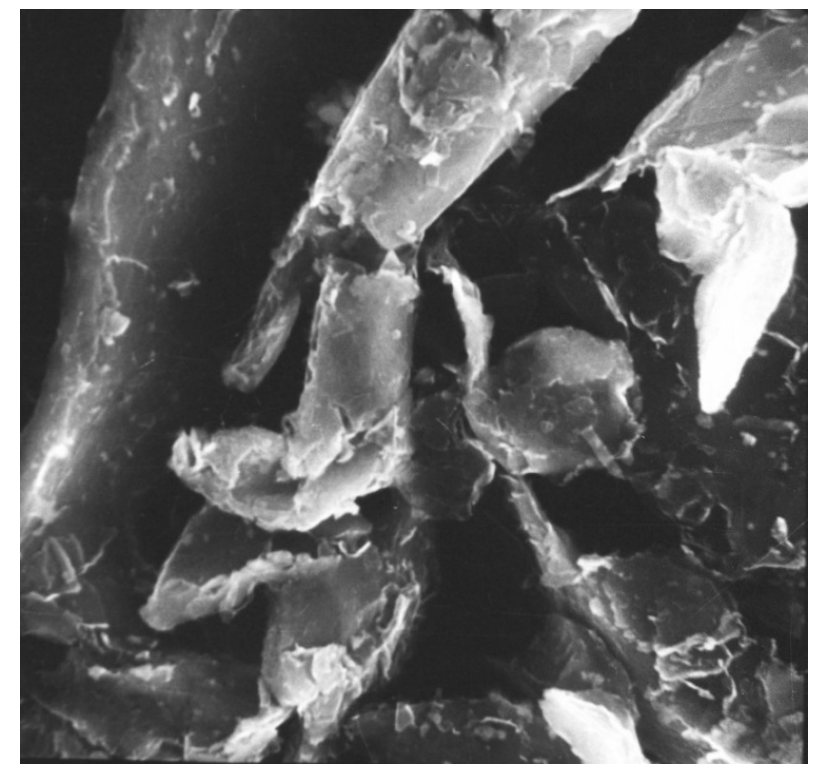

Figure 24 .

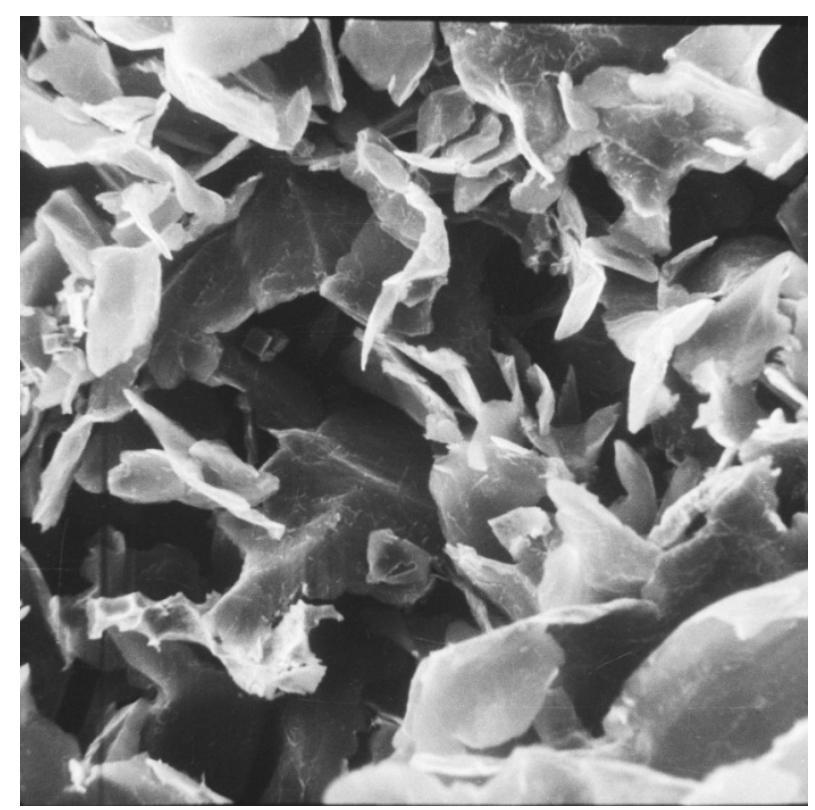

Figure 25. 


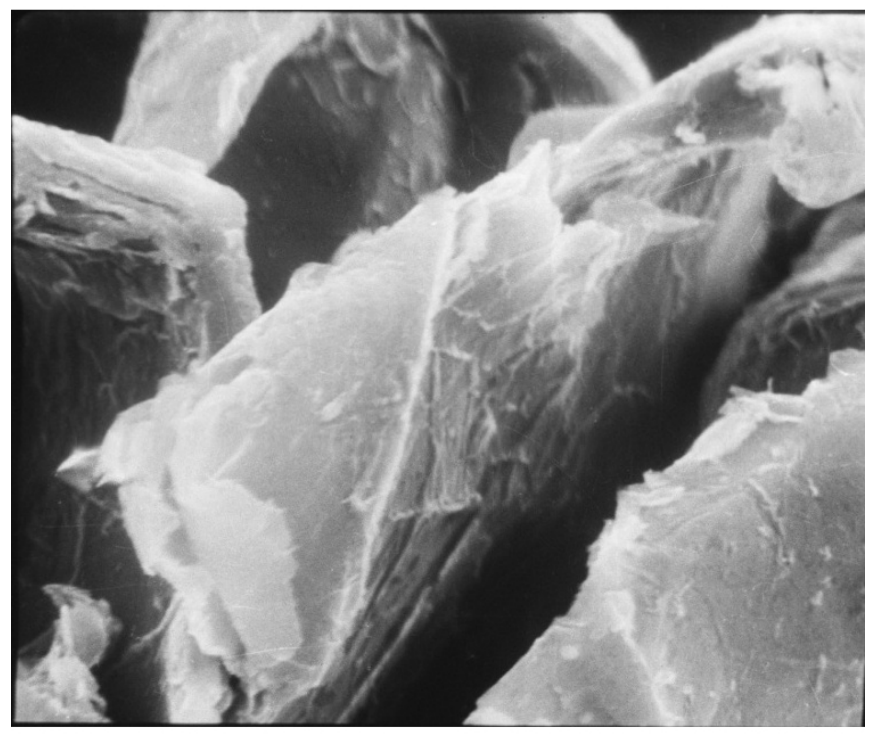

Figure 26.

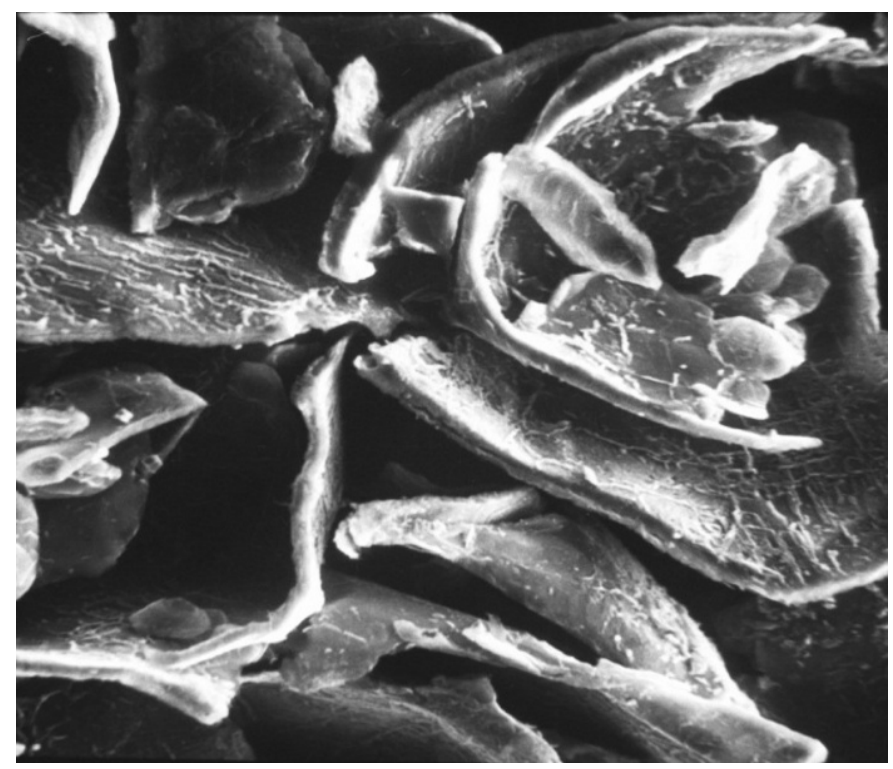

Figure 27. 


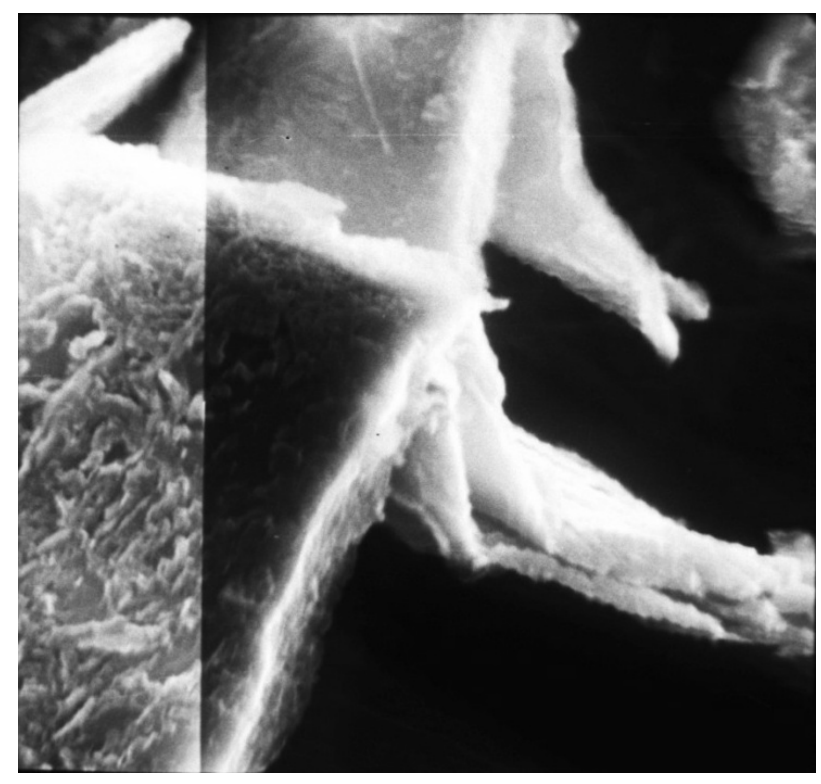

Figure 28.

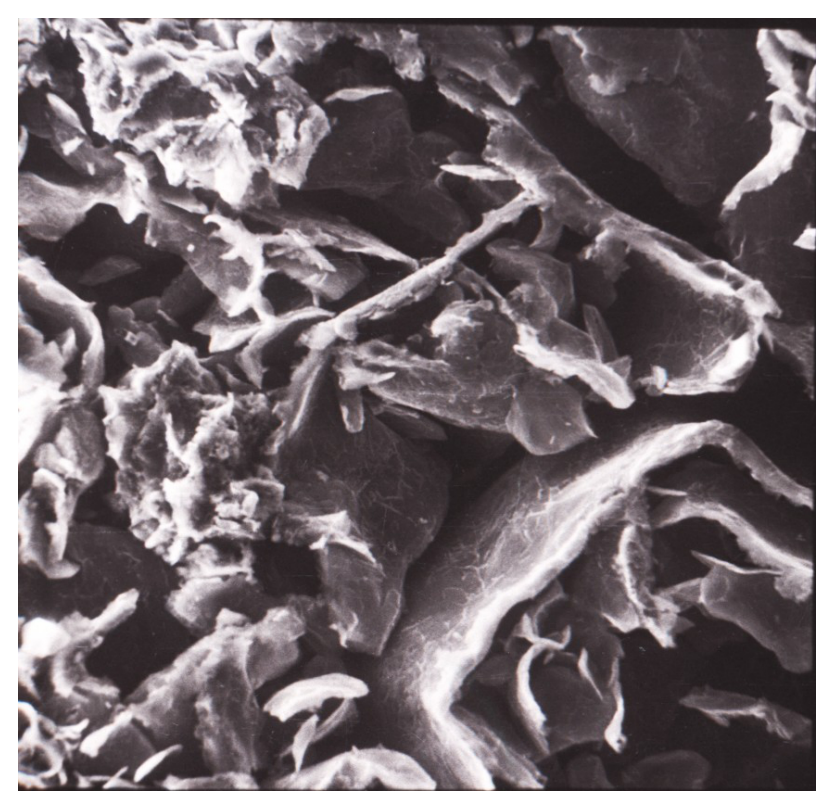

Figure 29. 


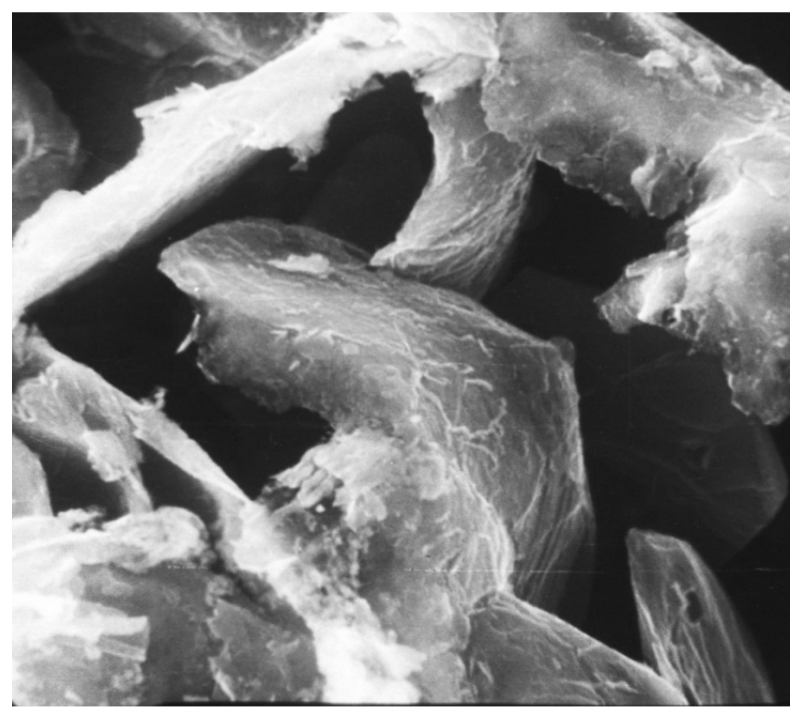

Figure 30.

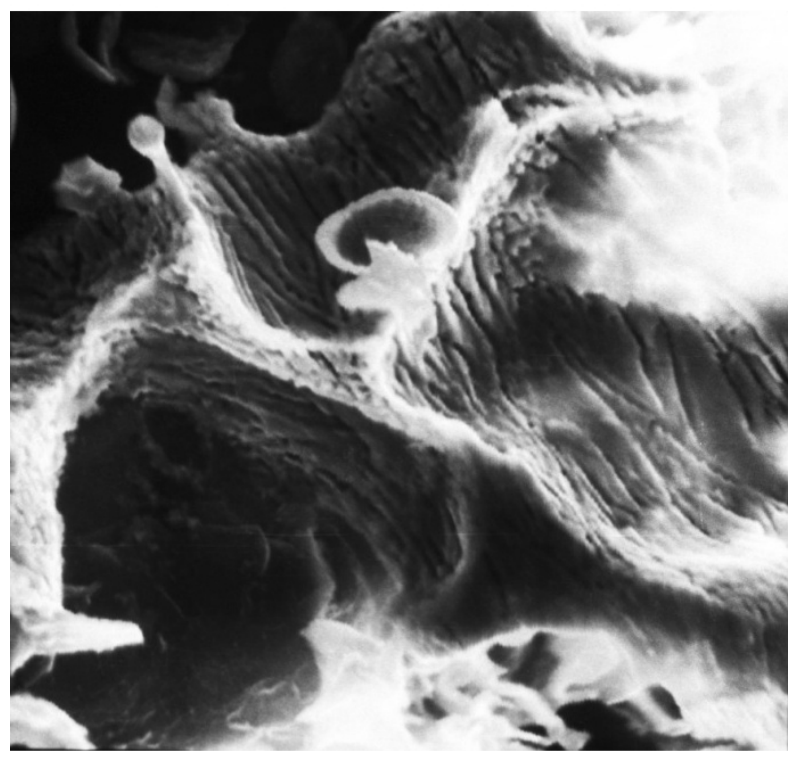

Figure 31. 


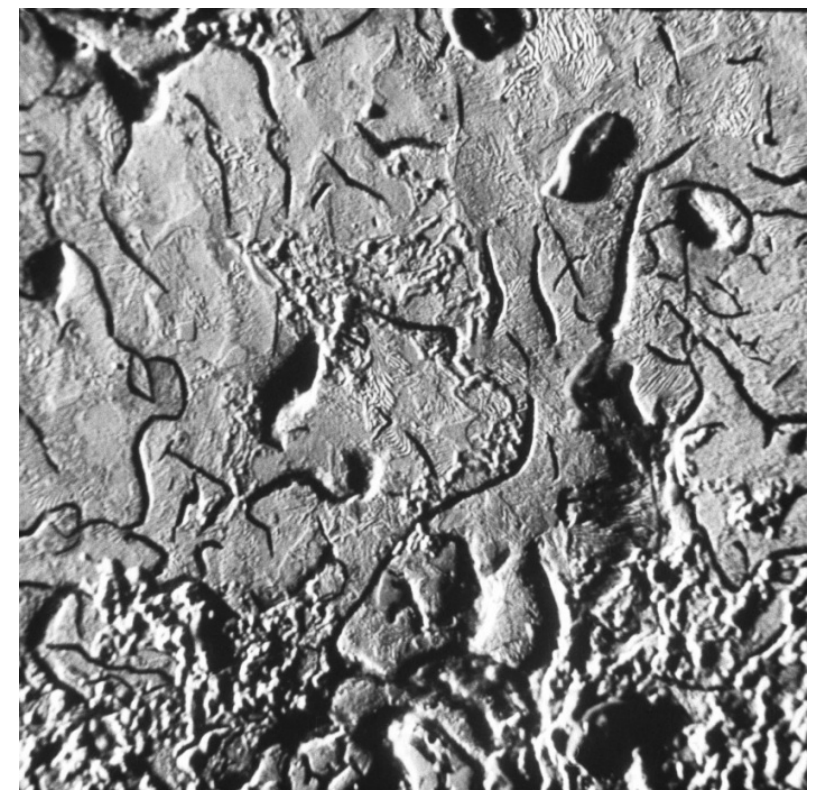

Figure 32.

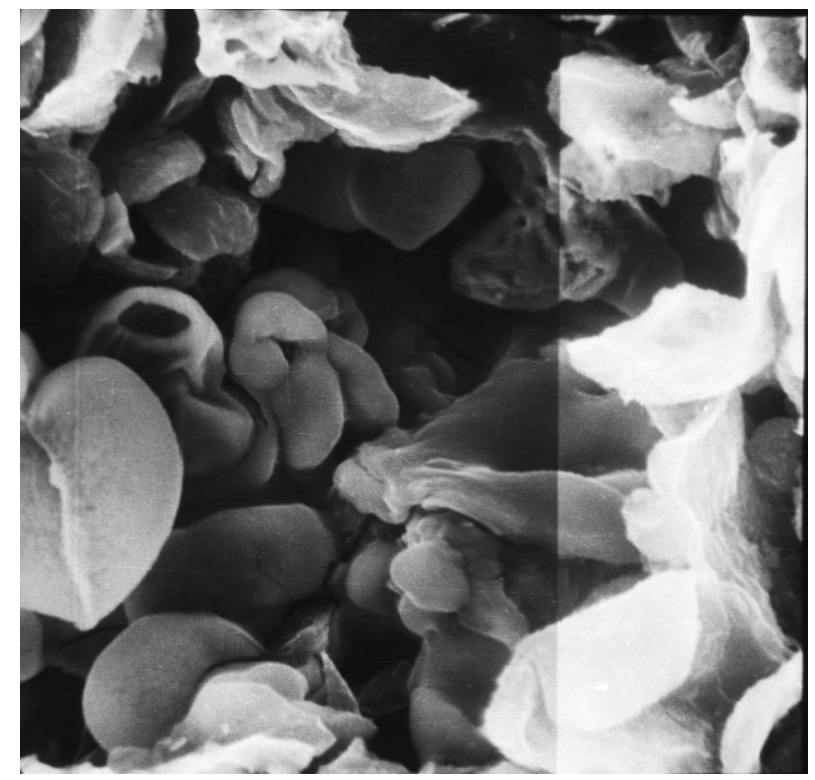

Figure 33. 


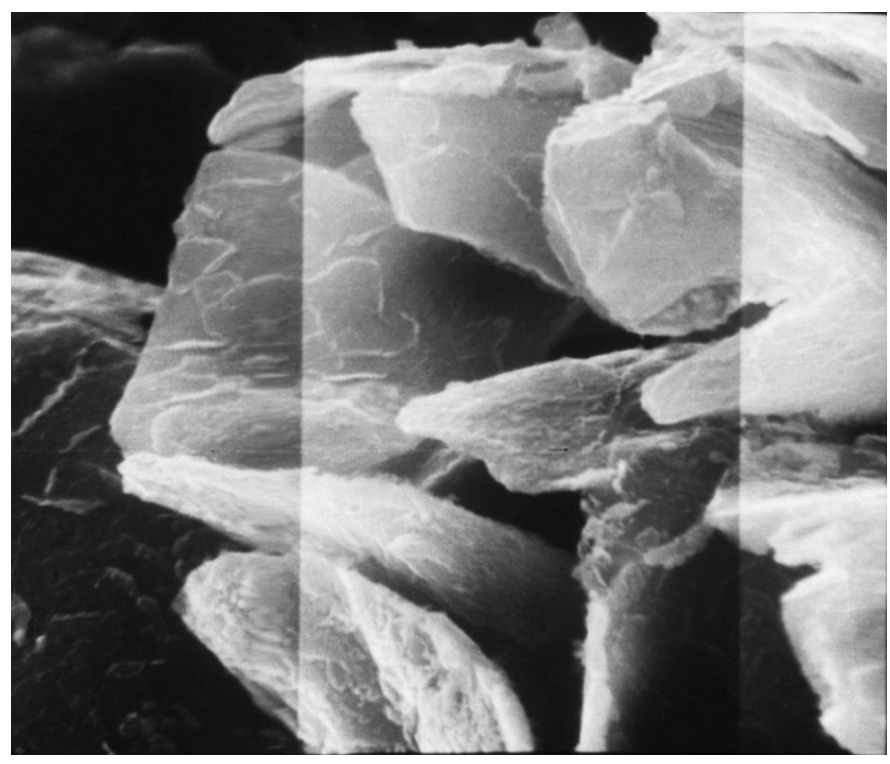

Figure 34 .

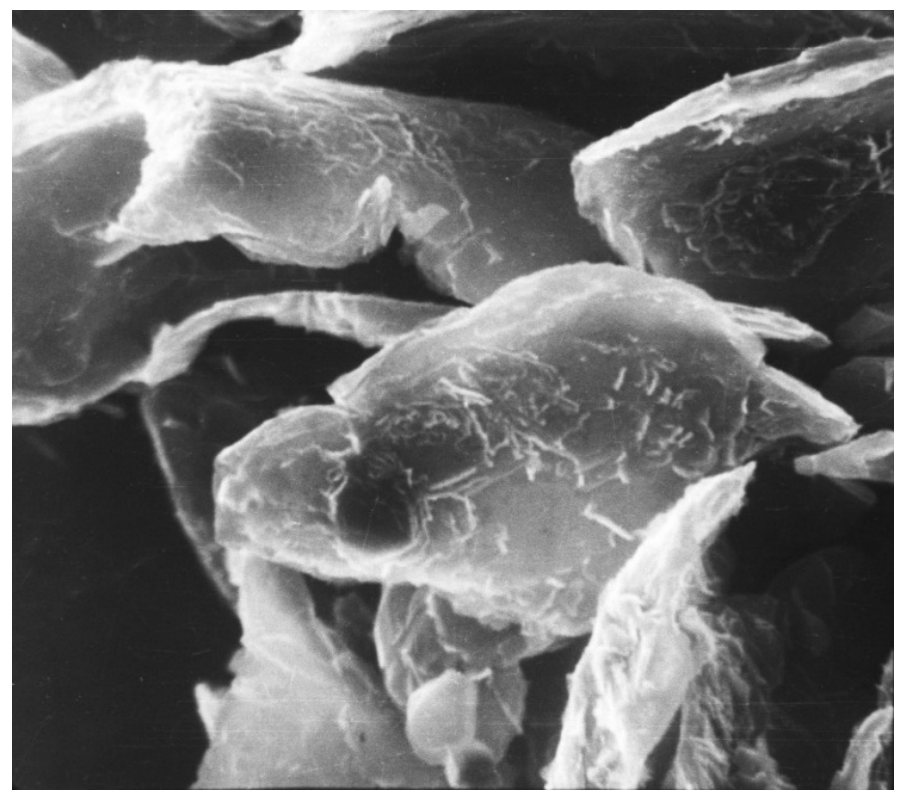

Figure 35 . 


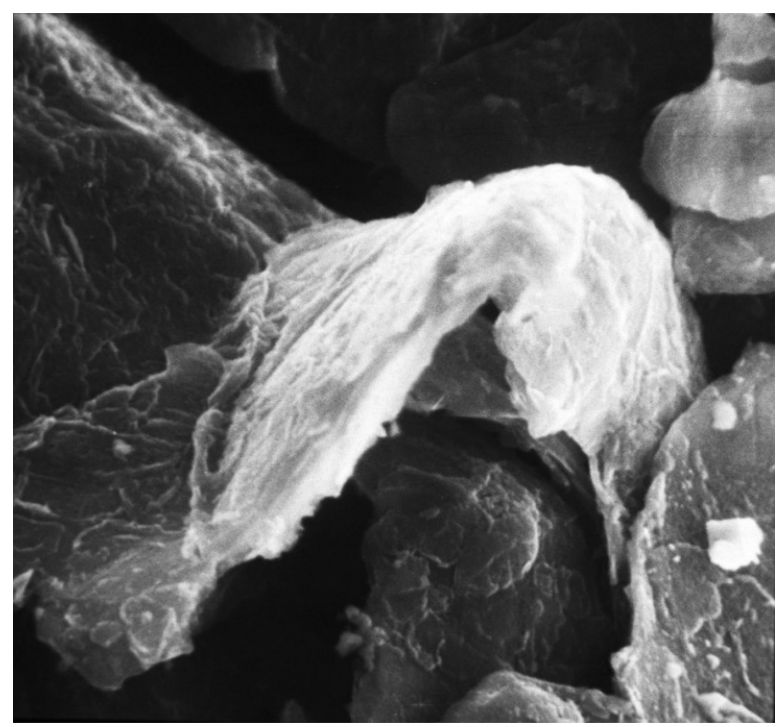

Figure 36.

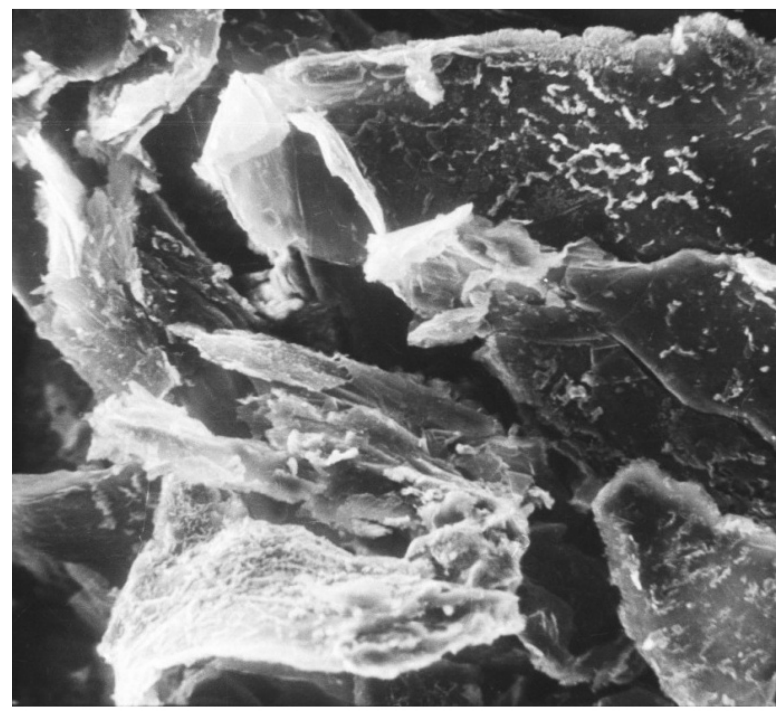

Figure 37. 


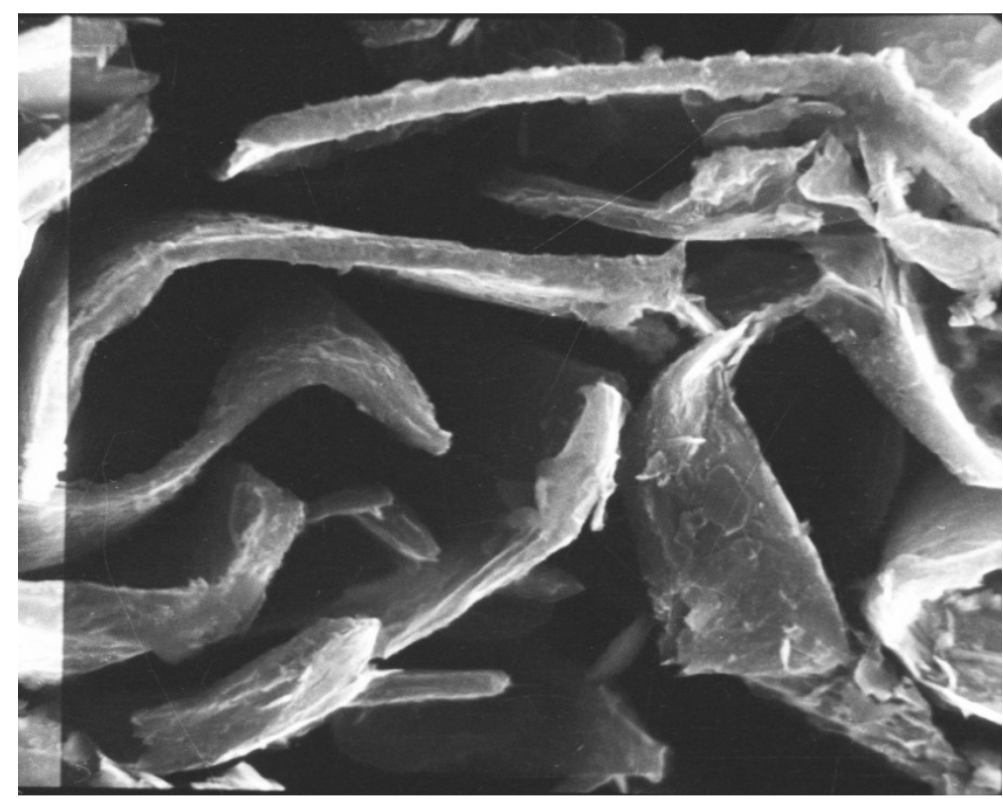

Figure 38.

The Hardness values bear very similar relationship with solidification time (Figs. 41 and 42).

B) On The Thermal Behaviour Of Molds (Figures 43 to 46)

Poor life of the molds has been the major reason for the slow progress of PM of ferrous and other high temperature alloys. The life of the mold is basically governed by the thermal cycle. Hence, a thorough understanding of the thermal behavior of the molds as affected by the operating parameters is very vital for the process designer. The thermal behavior also governs the extent and location of the defects in a given casting.

Studies on the thermal behavior aspects of metal molds during cast iron solidification indicate that the Volume Ratio (VR) is an important parameter in determining the thermal behavior of the metal molds. All the thermal behavior aspects considered (the interface temperature prior to air gap formation and during the final stages of solidification, air-gap formation time and the heat absorbed by the mold at the end of solidification), decrease gradually with an increase in the volume ratio but this decrease is not significant beyond a particular volume ratio. At a given volume ratio, an increase in either the mold or the pouring temperature causes an increase in the magnitudes of the above, thermal behavior aspects whereas the thermal behavior aspects are not significantly affected by the silicon content of the iron poured, in the range studied. 
- 1977 - In his AFS 1977 Hoyt Memorial Lecture, Rassenfoss talked about Mold Materials for Ferrous castings [43]. His observations were very relevant to present subject. He highlighted the huge costs involved in sand molding and sand reclamation. He also touched upon the problem of used sand disposal - that the dumpsites are getting farther and farther from the foundries and adding to the transportation costs. Problem of used sand dumpsites causing ill effects on the ground water and the streams nearby was serious, he observed.

Considerable effort and cost are involved in preparing the sand for Dump Worthiness. The advantages of PM process for ferrous castings on energy usage and environment were highlighted. He touched upon the various features of the Eaton Process. It was mentioned that although considerable efforts have been made to avoid chill formation in as-cast PM cast iron castings, no dependable practice has been obtained and for that reason all the castings need to be given an annealing treatment prior to machining / shipment. He quoted that Eaton and Kubota ltd. employ a high carbon equivalent (CE) for the permanent mold.

The use of Molybdenum dies for PDC of steel casting, and the usefulness of Graphite molds for ferrous castings were covered in his lecture. It was mentioned that graphite has a very low coefficient of thermal expansion and that it does not crack either on heating or cooling, and it does not heat check under even the most severe heating cycles. The problem with graphite is fragility and hence needs careful handling. According to him, in the US, about $16 \%$ of all iron castings are made in metal molds, and about $12 \%$ of all steel castings are made in graphite molds. He concludes by saying that with the economic and ecological advantages of PM, efforts will continue to adapt it to a greater amount for ferrous casting production in the future.

- 1982 - A publication by Cast -Tec Ltd [12], Ontario revealed that Europe was far ahead of USA in the production of iron castings in metal molds. The author reported that a study of literature accumulated at AFS and BCIRA could lead to assumption that USSR produced more than $15 \%$ of their ferrous castings in metal mold. The same was found to be true with Eastern European countries. The author also quoted that West Germany and Japan also cast considerable amount of cast iron and ductile iron castings in metal mold. The author claims that the process gained popularity and became practically viable after being dormant for nearly 60 years!!

- 1984 - A publication from Russel Cast-Tec [44] indicated that the company was able to offer PM castings in several grades of gray iron and Spheroidal Graphite (SG) irons. They claimed casting yield of over $90 \%$. SG Iron PM castings gave much higher nodule count than the corresponding sand casting. Their experience also showed that austempered SG irons could be produced in pearlitic grades by the PM process without the need for Nickel or Molybdenum alloy additions.

Another paper [45] jointly published by Cast-Tec Ontario, and Russel Cast-Tec., UK, claims a substantial cost reduction in PM process, compared with high - speed sand molding both in the casting and the product finishing. Reduced maintenance cost and rejection level have also been reported. To a question posed - "The advantages claimed of PM sound like a foundryman's dream. Why isn't it in general use?" - their answer was that in the past, many 
foundries were discouraged by high mold cost and poor mold life, and that has been the major hurdle. Their success, they claim, came from improvements in this area - one is the use of improved coatings and the other is the cleanliness of the iron poured that offers better fluidity that allows the mold to be filled easily at a lower temperature than the normal. This is a very significant point to be noted by those seeking similar improvements.

- 1988 - A book on cast iron by Roy Elliott [46] devoted a full chapter for PM of cast iron. Factors affecting the final microstructure of the casting and the mold life are discussed. Mention is made of the study conducted by Henych and Gysel, [47] on the thermal performance of the various die materials, and the merits of a high performance mold made from a copper-base alloy is highlighted.

- 1989 - Another publication by M/s Cast -Tec [48] revealed that the technology developed by them (Cast-Tec's Permanent Mold Technology - a patented system) became a viable reality in 1978 and that a large number of components of gray and ductile iron castings - that included compressors, engine crankshafts, connecting rods, steering knuckles and components, hydraulic components, pump housing, pulleys, brake rotors, refrigerator cranks, electric motor end frames, hub type castings, brake carriers, golf club heads, pipe fittings, etc. were being produced on a regular basis since then.

- 1990 - The authors of the present paper introduced the technology of PM of cast iron in a newly established automotive component manufacturing company (Allparts Castings Limited), in Kenya. The components manufactured included brake rotors \& brake drums (for various Japanese, European and American models of cars, light commercial vehicles and trucks), and a variety of engineering components. The weight range covered was from $5 \mathrm{~kg}$ to nearly $100 \mathrm{~kg}$. A typical brake drum made by them using PM process is shown in Fig. 47.

Test reports (from Germany) confirmed the superior properties and field reports confirmed superior performance of these PM products compared to sand cast equivalents. In the case of both brake rotors and drums, the users confirmed better braking efficiency.

A project on PM of cast iron, as a part of the Masters Degree Program, University of Nairobi, was carried out at the plant [49], and considerable data were generated under production conditions. The findings were presented in a workshop under UNIDO Innovation Technology Management Program in Nairobi, in 1977 [50].

During 1990 to 2002, PM cast iron tonnage poured at Allparts castings Limited was in excess of 15000 tons.

Some of the practices followed at Allparts Castings Limited, and Experience gained.

- All the components made were of hypereutectic cast iron, inoculated prior to pouring.

- Molds were made of desulfurized, hypereutectic cast iron with \% S less than 0.05 ,

- Most mold were made of 2 parts, either top-bottom or left-right type.

- All the castings were top poured (through the riser). To improve die life, the portion where the metal stream first strikes the bottom mold, was made of a separate replaceable metal insert, and in some cases, made of a dispensable pad of Shell sand. 
- The mold coating used was a water base silica flour spray, sprayed for each pour. Where situation demanded, a thick shell resin sand coating was employed to reduce the cooling rate.

- Mold temperature of $200-250^{\circ} \mathrm{C}$, and Pouring temperature of $1300-1350^{\circ} \mathrm{C}$ was employed in most cases. However, in some special cases, to achieve a slower cooling rate, a higher mold temperature was employed through continuous external heating with gas.

- Draft angle provided in the casting was minimum $1^{\circ}$ for easy extraction. Easy extraction meant less of stresses in the castings.

- The castings were removed from the mold in red - hot condition and cooled under a layer of sand. This was to get an annealing effect, without resorting to costly and time - consuming heat treatment process.

- Multi-Part metals cores were used in most cases. In some special cases, sand cores were used (hollow cores wherever strength of the core permitted, to reduce sand usage). In cases where the core was in contact with the working surface (like in the case of Brake Drums), the working surface of the metal core was provided with a large number of $1 \mathrm{~mm}$ deep pockets, in thermosetting resin sand was filled (this resin sand layer was replaced for each pour). In such cases, each mold had two sets of metal cores.

- The mold failure was invariably due to thermal fatigue cracks (Fig 48). Where the mold crack area corresponded to machined surface of the casting, the mold was not discarded at the initial appearance of cracks, but continued in production until the cracks become too severe and unmanageable, or the die broke into pieces. Moreover, minor, hairline cracks get covered by the mold coating.

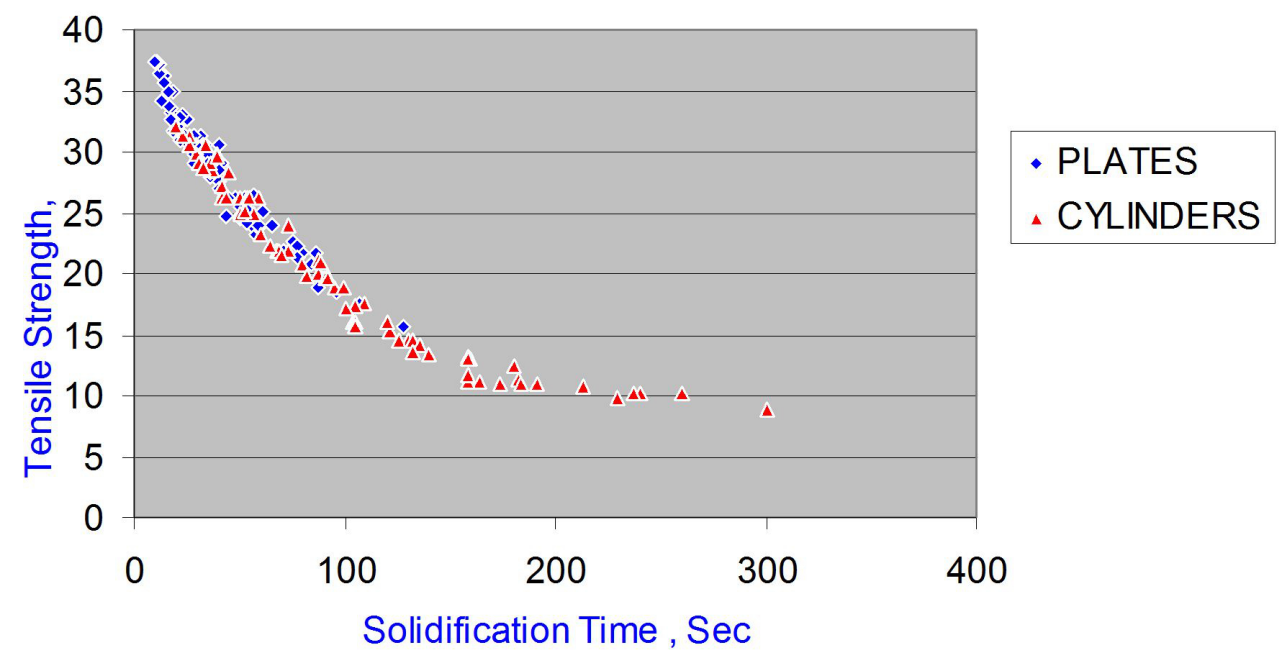

Figure 39. Tensile Strength (Kg / Sq. cm) Versus Solidification Time, for both Plates and Cylinders. \% Si = 3.00. 


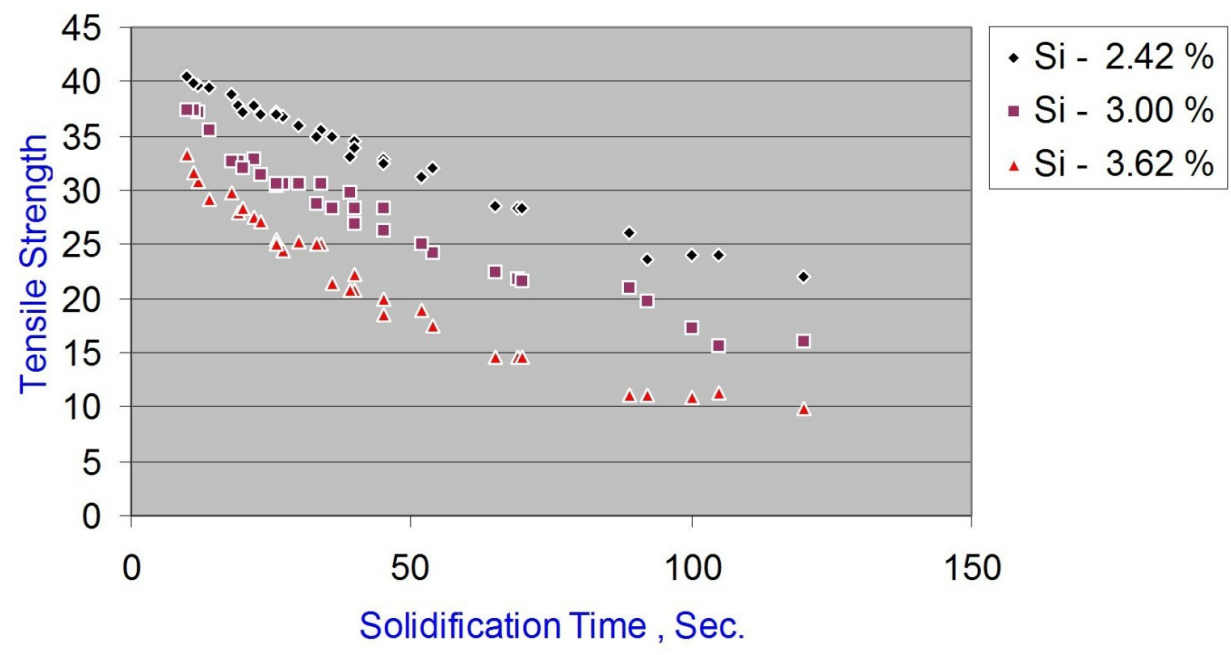

Figure 40. Tensile Strength (Kg / Sq. mm) Versus Solidification Time for both Cylinders and Plates, for Different Si \%. M.T. $=150^{\circ} \mathrm{C}$, P.T. $=1250^{\circ} \mathrm{C}$.

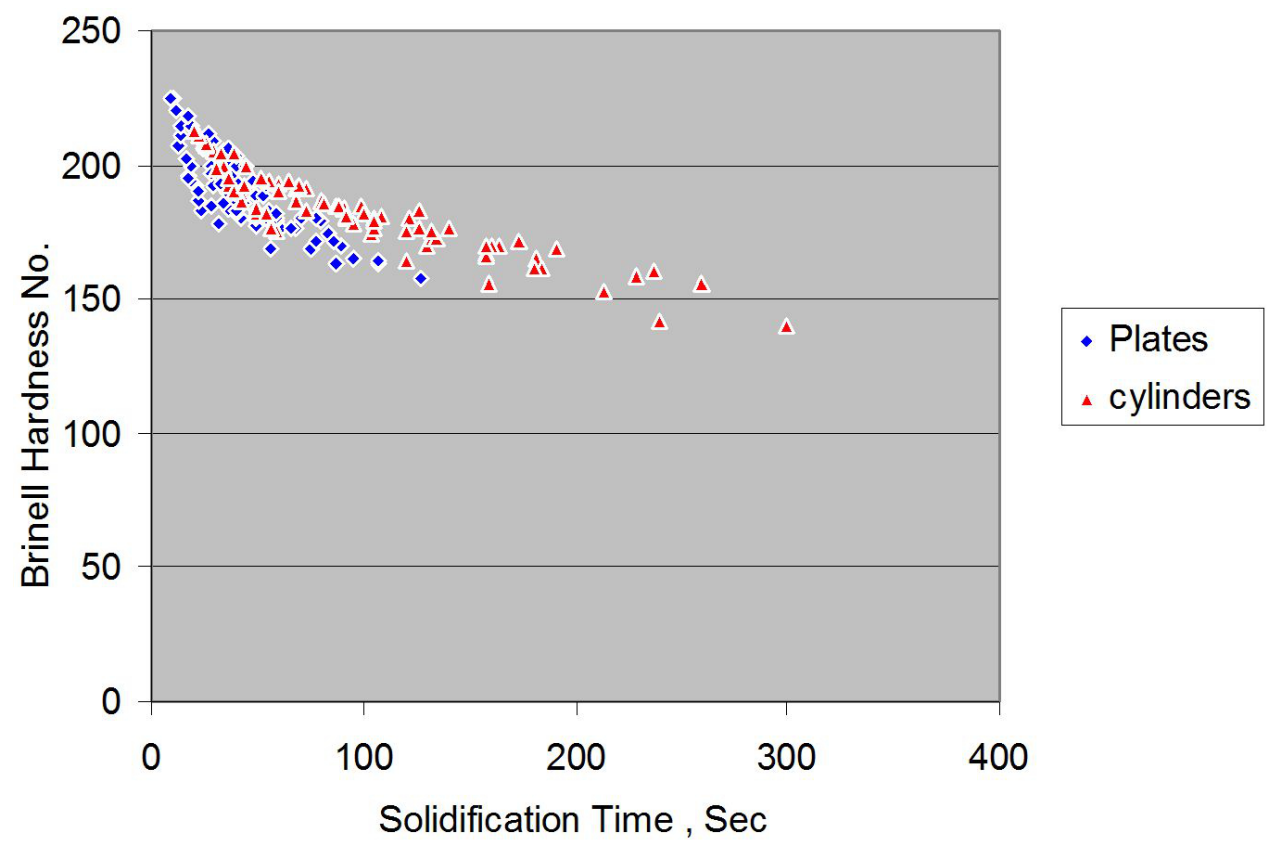

Figure 41. Brinell Hardness Versus Solidification Time for both Plates and Cylinders, \% Si $=3.00$. 


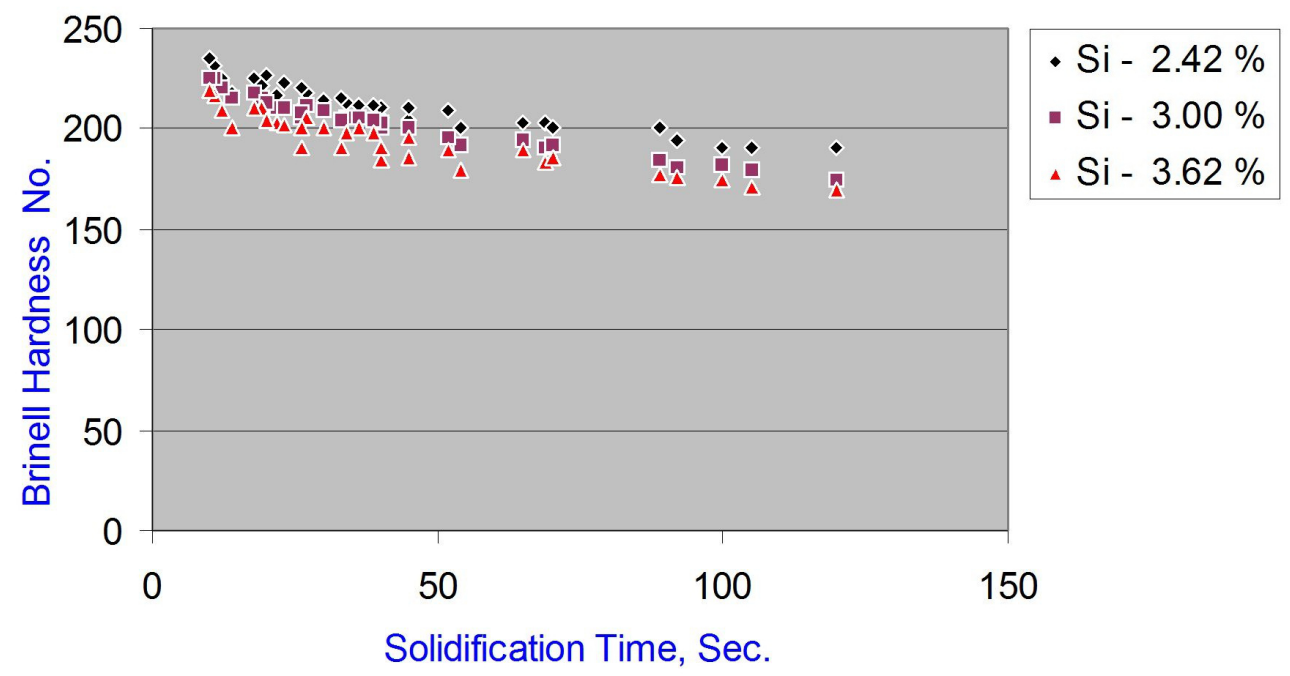

Figure 42. Brinell Hardness Versus Solidification time for both Cylinders and Plates, for different $\mathrm{Si} \%, \mathrm{MT}=150^{\circ} \mathrm{C}$, $\mathrm{PT}=1250^{\circ} \mathrm{C}$.

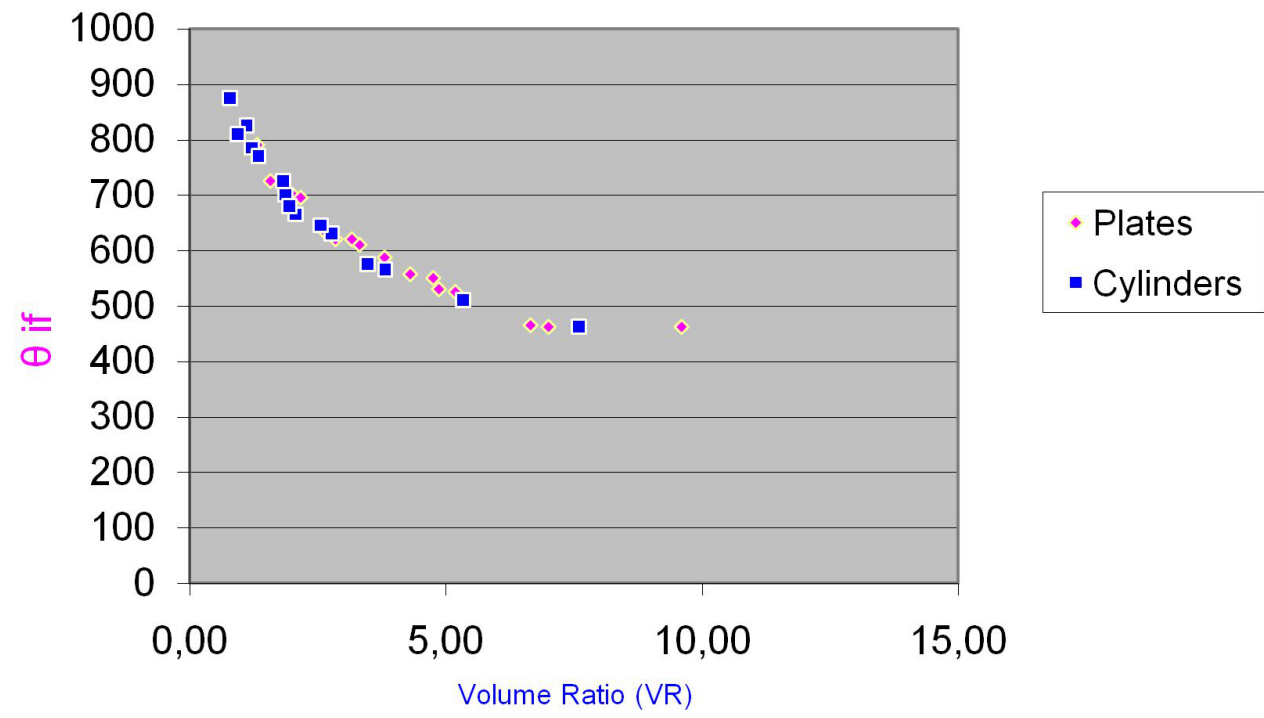

Figure 43. Interface Temperature $\left(\theta i f{ }^{\circ} \mathrm{C}\right)$ During The Last Stages Of Solidification Versus Volume Ratio (VR). \% $\mathrm{Si}=3.00, \mathrm{M} . \mathrm{T} .=150^{\circ} \mathrm{C}$, P.T. $=1250^{\circ} \mathrm{C}$. 


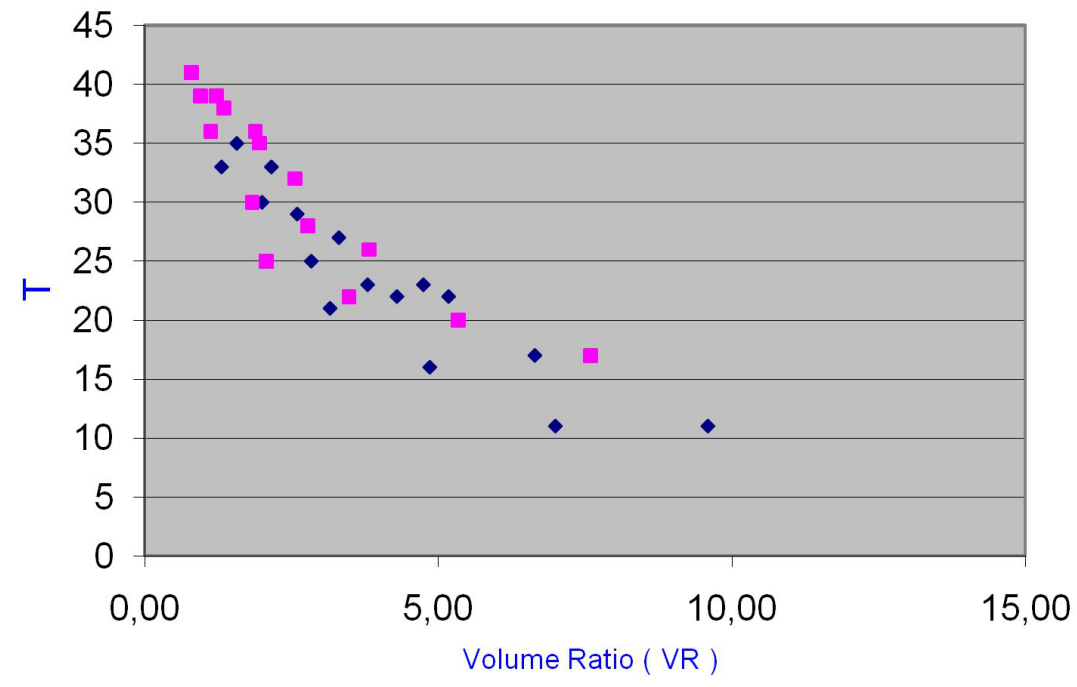

- Plates

Cylinders

Figure 44. AirGap Formation Time (T, Sec) Versus Volume Ratio (VR). \% Si=3.00, M.T. $=150^{\circ} \mathrm{C}, \mathrm{P} . \mathrm{T} .=1250^{\circ} \mathrm{C}$.

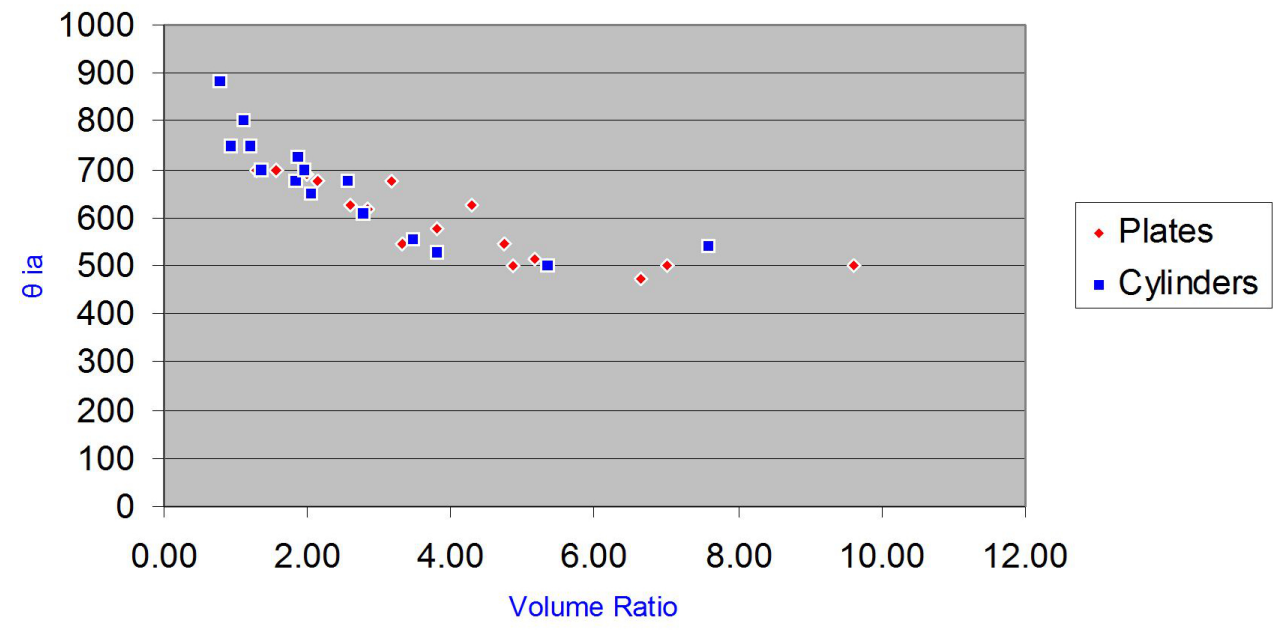

Figure 45. Interface Temperature, ${ }^{\circ} \mathrm{C}$,Prior To Air Gap Formation ( $\left(\mathrm{ia}^{\circ} \mathrm{C}\right.$ ) Versus Volume Ratio (VR). \% $\mathrm{Si}=3.00, \mathrm{M} . \mathrm{T} .=$ $150^{\circ} \mathrm{C}$, P.T. $=1250^{\circ} \mathrm{C}$. 


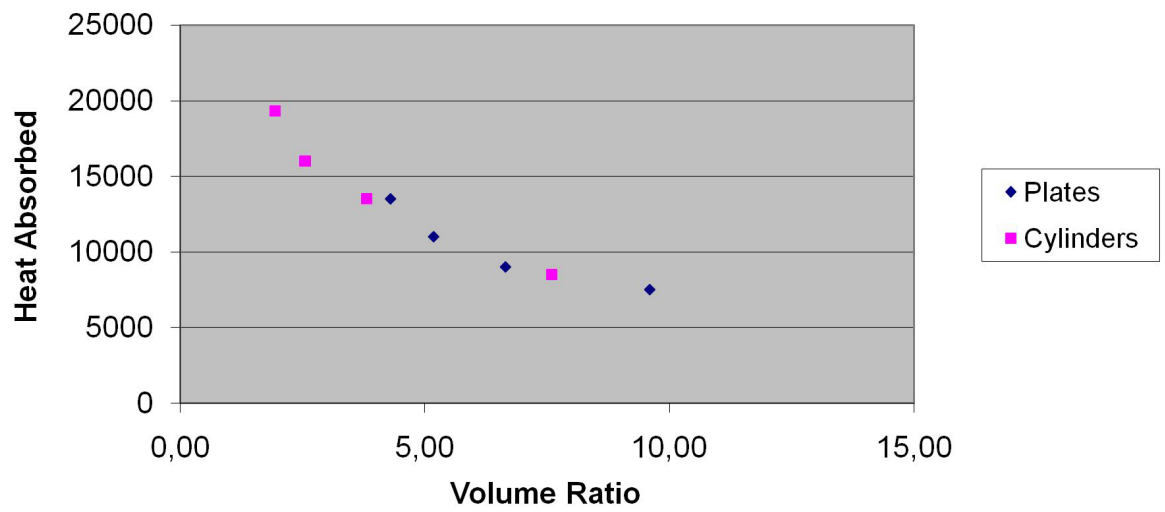

Figure 46. Heat Absorbed by the mould at the end of solidification (K.Cal / Sq.M) Versus Volume Ratio.

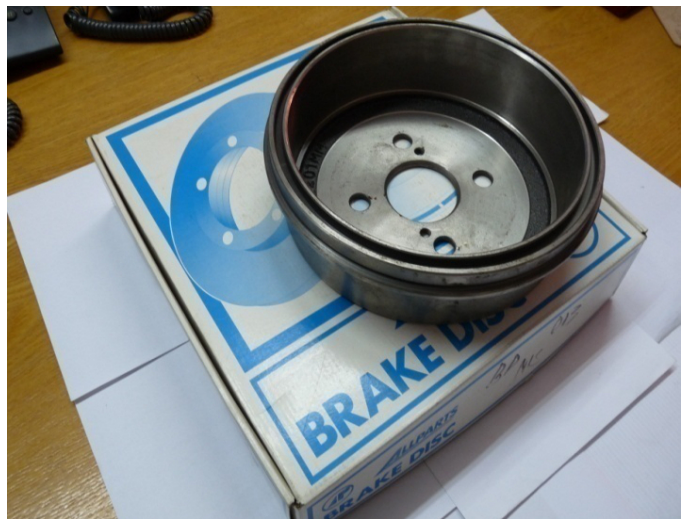

Figure 47. A Brake Drum made by PM process.

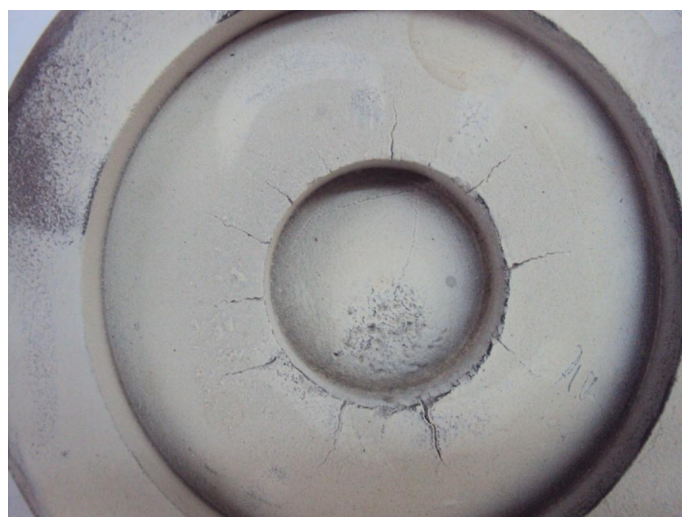

Figure 48. Typical Thermal Fatigue Cracks in a PM. 
- Considering the strength requirements of the mold during handling in hot condition, in most cases the mold wall thickness was kept more than demanded by thermal considerations. Hence most dies with cracks on the working surface were salvaged, by re-machining. Multiple salvaging was possible.

- The totally damaged mold were simply re-melted to make new molds.

- The casting yield was more than $95 \%$, and many cases, the castings were riser-less.

- The parts produced by this process showed a much higher wear resistance compared to equivalent sand cast part. An example of a brake rotor for Land Rover 110 is shown in Fig. 49.

- Where the specification demanded a little higher $\%$ of pearlite, addition of small $\%$ of Sb and $\mathrm{Cu}$ were tried as per the hints given in the literature $[13,46]$ and the results were extremely encouraging.

- In some very thick castings, even under the fast cooling conditions, it was not possible to achieve predominantly Type D graphite on the working surface as specified. Here again, a hint given in one publication [13] came to the rescue - addition of $0.1 \%$ Ti settled the matter to the fullest satisfaction.

- Generally Brake Rotors and Brake Drums made from sand castings are machined all over to achieve a good dynamic balancing. It was found that in PM castings, with machining on only working surface and the fitting surface, and leaving the rest as-cast, a good balancing was still possible. Even on the machined surfaces, the machining allowance in most cases was $1 \mathrm{~mm}$ only.

- Quality of both the castings and the machined components was extremely good - in most cases, the overall rejection was under $2 \%$. Machinability was very good - higher speeds \& feeds, good surface finish, retention of sharp corners and edges, smoother thread formation, reduced tool consumption, and so on. Normally Brake Rotors and Drums are removed from the vehicle many times during its life, for re-skimming the working surface. In the case of those with threaded bolt - holes, the threads get damaged easily during removing and fixing. The feedback from customers showed that such thread wearing in PM cast components was virtually absent, where as it was quite common in sand cast equivalent. The thread formation in PM castings is very smooth due to fine Type D graphite, where as in sand castings with coarse Type A graphite smooth threads are not possible due to graphite pullout [15].

- The PM components were at least $30 \%$ cheaper than the equivalent sand cast components, as applicable to Kenyan conditions.

-1996 - A very valuable publication (possibly the most informative of all the publications, touching upon both the thermal and metallurgical aspects), on Ferrous Permanent Mold (FPM) process, by Lerner [13] highlighted the various developments in the recent years. Advantages of the process in terms of Cost, Quality, Energy Reduction and Environmental Issues have been addressed. The author mentions that in addition to superior casting finish and dimensional tolerance, the process has various other distinct advantages like: 
a) Gas and shrinkage porosity-free structures for leakage-free castings needed in hydraulic and gas components' applications. Pressure tests routinely performed on these castings showed little or no rejection.

b) Reduced production time, reduced finishing costs, elimination of sand and sand handling, and improved dimensional accuracy and stability.

c) Castings have a history of exceptional machinability, very low rejection on machining, ability to hold close tolerances.

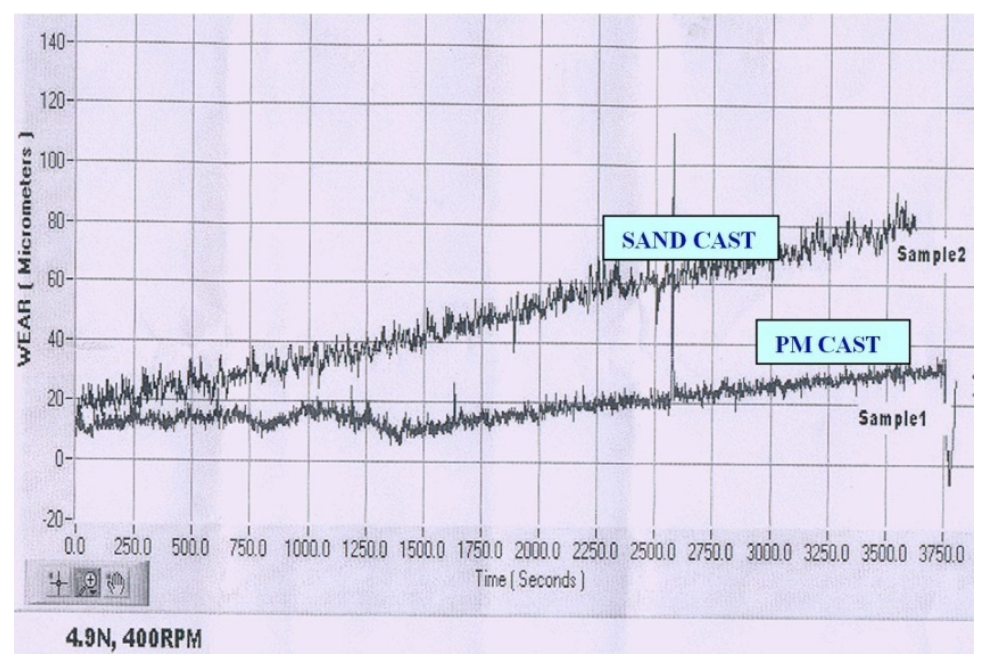

Figure 49. Typical example of relative wear pattern of a brake rotor of Land Rover 110 - cast in sand mold and permanent mold.

The author reports that PM gray iron castings can give 30000 psi tensile strength with 147$201 \mathrm{BHN}$ hardness in a fully ferritic matrix containing predominantly type D graphite. Basically the castings are strong yet machinable. For SG iron PM castings, the amount of Mg that has to be added is less than for sand castings. This results in lower residual content, which in turn results in controlled shrinkage, improved nodularity thus enhancing mechanical properties and better overall casting quality.

Some statistics provided by the author on the production volumes of PM castings world over is very useful indicator of the progress made in recent years. The figures are as follows:

Europe - 15 foundries with estimated annual production of 35000 tons, Eastern Block (former Soviet Union, Czech Republic, Poland, Hungary, Bulgaria) - 650000 tons, a new German owned foundry in Brazil - 12000 tons of gray iron and 6000 tons of ductile iron, Japan at least 6 foundries, 18000 tons, two Japanese built foundries - one in Malaysia and the other in China with a combined production of 6000-8000 tons, two foundries in India with low volumes, a few foundries in Canada and U.S.A (including Perm Cast in Kentucky - the orig- 
inal Eaton Corp., Honda of America, Anna, Ohio).It is reported that Honda of America began producing ductile iron steering knuckles on an automatic FPM line ( Quick Cast Knuckle-QCK ) in the fall of 1995 and casting production via this process is of the order of 22 tons per day. The author has provided list of components made by these several above foundries in addition to a very detailed list of FPM castings made by former USSR.

The author has also touched upon some metallurgical aspects PM cast irons. In addition to the value of $\mathrm{C}, \mathrm{Si}, \mathrm{Mn}, \mathrm{P}$ and $\mathrm{S}$ specified for PM gray cast iron, he has touched upon the addition of small quantity of $\mathrm{Ti}(0.02$ to $0.10 \%)$. He states that $\mathrm{Ti}$ is essential for providing the under-cooling required to meet ASTM Specification A 823-84, that calls for predominantly type D graphite with some type A graphite associated with the center line or around sand cores. However, if desired cooling rate is can be obtained in the mold by using a more effective cooling system, the Ti content in the base iron may be on the lower side of the above mentioned range (This particular effect of Ti was in fact, experienced in the commercial production at Allparts Castings Ltd). A high CE (carbon equivalent) is needed to regulate chill depth and reduce sink / lap type defects. Inoculation, if used, is strictly for the chill control, as type A graphite is not desired, observes the author. All FPM mold castings are heat treated as per ASTM std. $823-84$. Some castings are annealed at $843-927^{\circ} \mathrm{C}$ for $1 \mathrm{hr}$ and furnace cooled to obtain fully ferritic matrix, while the rest are normalized at $816-927^{\circ} \mathrm{C}$ for $1 \mathrm{hr}$ and air quenched. The microstructure of a normalized FPM usually has $10-30 \%$ pearlite. If a higher $\%$ of pearlite is required, it may be obtained by small additions of Antimony (Sb). Taking a hint from this, small $\mathrm{Sb}$ additions was practiced for some brake rotor castings at Allparts Castings Ltd.

According to the author, one major obstacle restricting the widespread adoption of FPM is the relatively short mold life encountered in casting ferrous alloys (this is a very significant point to note for future research work). This problem is reduced by the use of Lined Permanent Molds (LPM) where the working surface of the mold is lined with a thin layer of slurry or sand mixture depending upon the alloy poured. This practice not only increases the mold life, but also reduces / eliminates carbides in the structure (again, taking a hint from this paper, such methods were employed for some components at Allparts Castings Ltd., with a great degree of success). However, if high wear resistant chilled iron microstructure is desirable, like in automotive camshaft applications, the portions corresponding to the eccentrics are not lined and the molten metal comes directly in contact with mold. The author says that LPM process is quite popular in former Soviet nations.

The author mentions that the thermal effects of the liquid metal flow in the mold are the major factors in determining the mold life as well as the casting quality. This fully justifies the earlier study conducted by the present authors on the thermal behavior of metal molds.

Learner adds that by and large, a gray iron with type A graphite is recognized as a good material for the mold. Research to improve mold life showed that the highest resistance to thermal shock was exhibited by $\mathrm{Cr}$-Mo containing gray iron. The same was the experience at Allparts Castings Limited as mentioned earlier on. Type A graphite raises the thermal conductivity of the mold, while $\mathrm{Cr}$ and Mo increase the metallic matrix heat and thermal fatigue resistance. 
- 2004 - Technikon LLC, that operates the casting Emission Reduction Program (CERP) published the findings of their research on the durability of metal molds used for high temperature alloys like Iron, Steel, Nickel and Titanium [1]. They observed that the principal drawback to the application of PM to castings of these high temperature alloys is a short mold life. The shortened life is caused by the thermal shock when the molten metal is poured, as well as wear produced in the removal of the previously used mold coatings. This durability problem is the main reason behind the slow progress of PM of ferrous castings. The publication covers methodology used to candidate alloys for evaluation as a high temperature permanent mold insert material. The results of the manufacturing of the test die blocks / coupons by a process known as laser consolidated powder deposition, for each of the candidate alloys is discussed in the report. The findings clearly indicate that the service life (cycles) of the permanent mold drops as the pouring temperature is increased. A case involving iron metal mold in which castings were made of different alloys are presented (Table 5). Eight different mold materials have been compared in respect of conductivity, hardness, melting point, phase / volume change, eutectic reaction, cost, machinability and repairability. Further studies are planned.

\begin{tabular}{ccc}
\hline Alloy System & Melting Temp $\left({ }^{\circ} \mathrm{F}\right)$ & Casting Runs / Service life \\
\hline Titanium & 3270 & 250 \\
\hline Iron & 2802 & 500 \\
\hline Nickel & 2651 & 700 \\
\hline Copper & 1981 & 4000 \\
\hline Aluminium & 1220 & 100000 \\
\hline Magnesium & 1202 & 110000 \\
\hline Zinc & 787 & 500000 \\
\hline
\end{tabular}

Table 5. Melting Temperature of Alloys Poured Versus Estimated Service Life (cycles) for Iron Molds.

- 2008: The PM process for cast iron was established at Abilities India Pistons\& Rings, Ghaziabad in the out skirts of New Delhi. The castings made are presently limited to some of their own in-house requirements of fixtures for machining. The company is now working on the prospects of developing various PM cast iron components for domestic and export market. The fist step taken towards this is educating the customers on the on the merits of the process.

Some of the microstructures (both Optical and SEM) observed in the various production castings are given in Figures 50 to 57. 


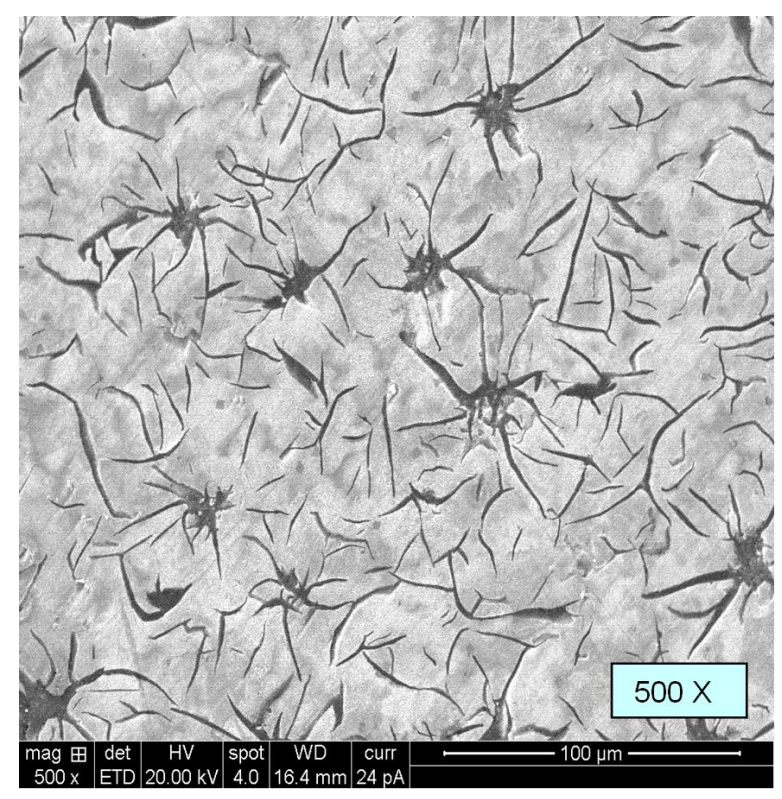

Figure 50. Flake graphite adjacent to the core in a hollow cylindrical casting.

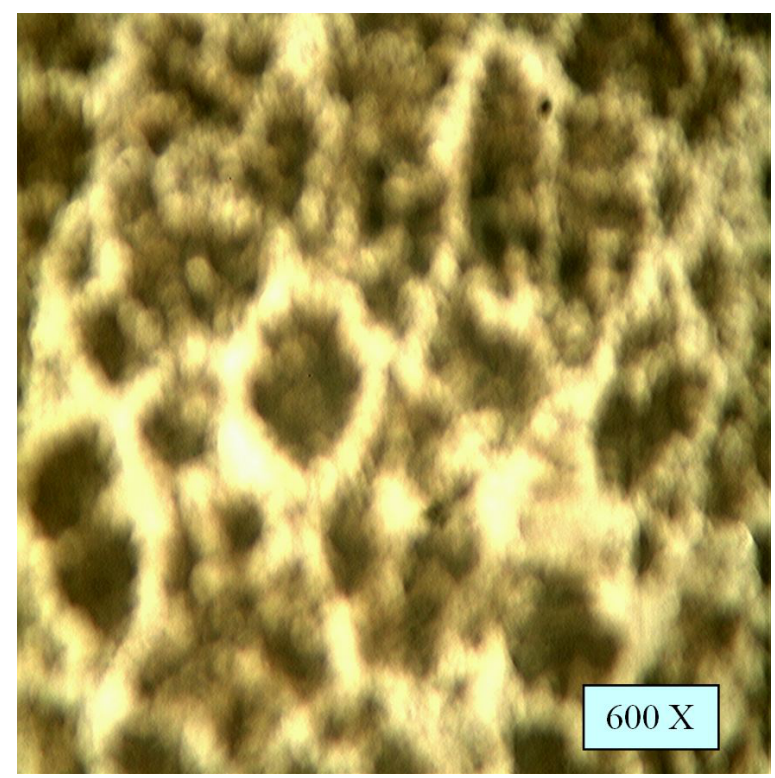

Figure 51. Eutectic Cells. 


\section{Way Forward Towards Enhancing the Production of PM Cast Iron}

It becomes the sacred duty of all researchers and practitioners of foundry, to work together in this direction, create awareness and share their experiences to make the Permanent Molding of Cast Irons a totally viable process for mass production. Foundry industry has to work harder, to be recognized as a sustainability leader by other industries and the public.

An International Expert Committee consisting of leading foundry personalities may be formed, to work out modalities to bring awareness on the subject, collect detailed statistics through world foundry associations, and to suggest practice based research programs, with some time bound plans of action. The development of better mold materials and ways to improve the mold life need to be tackled on priority.

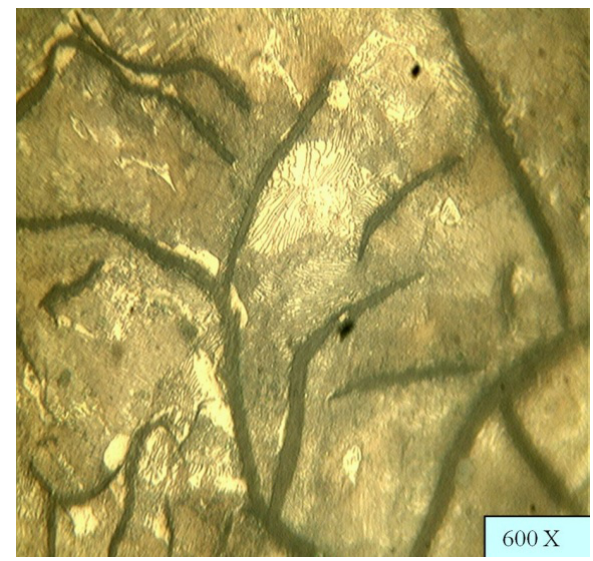

Figure 52. Flake graphite in a pearlitic matrix adjacent to the core in a hollow cylindrical casting.

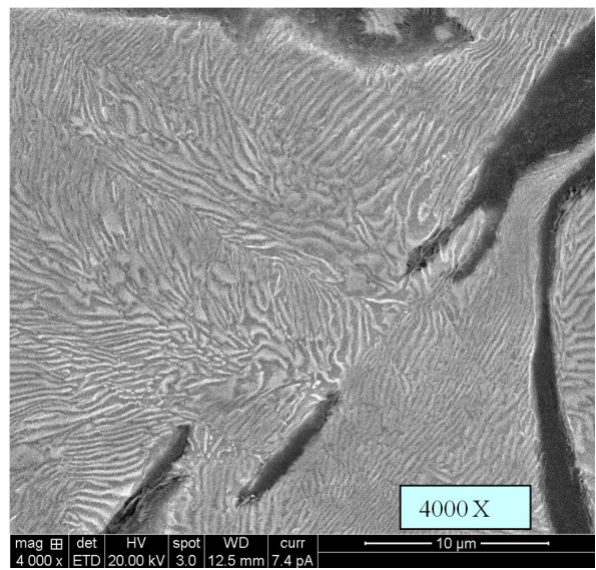

Figure 53. Pearlitic matrix adjacent the core in a hollow cylindrical casting. 


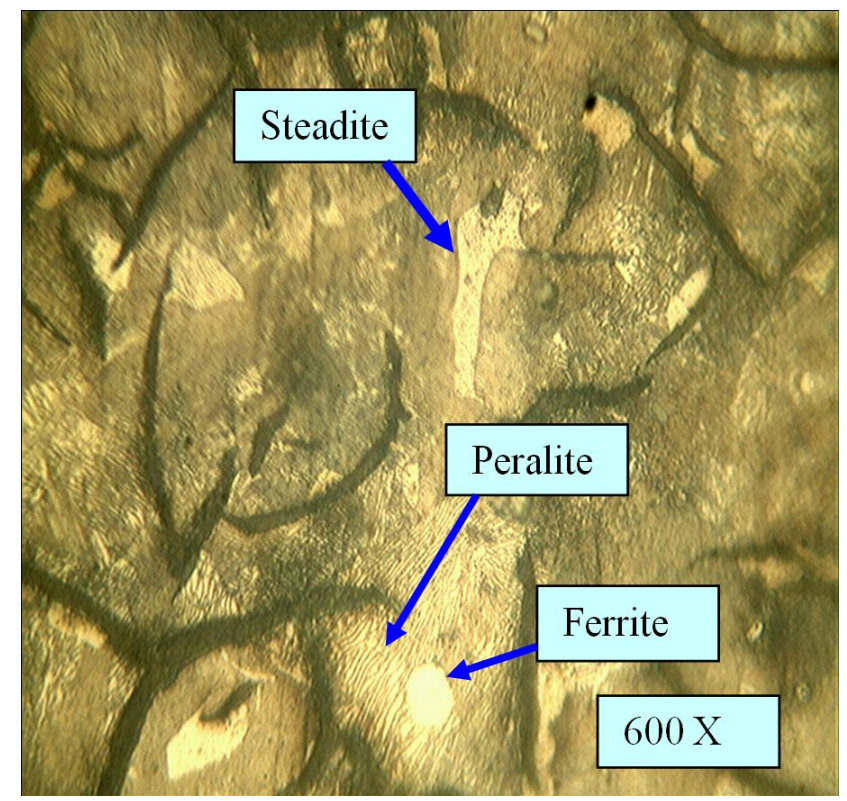

Figure 54. Steadite, Pearlite and Ferrite.

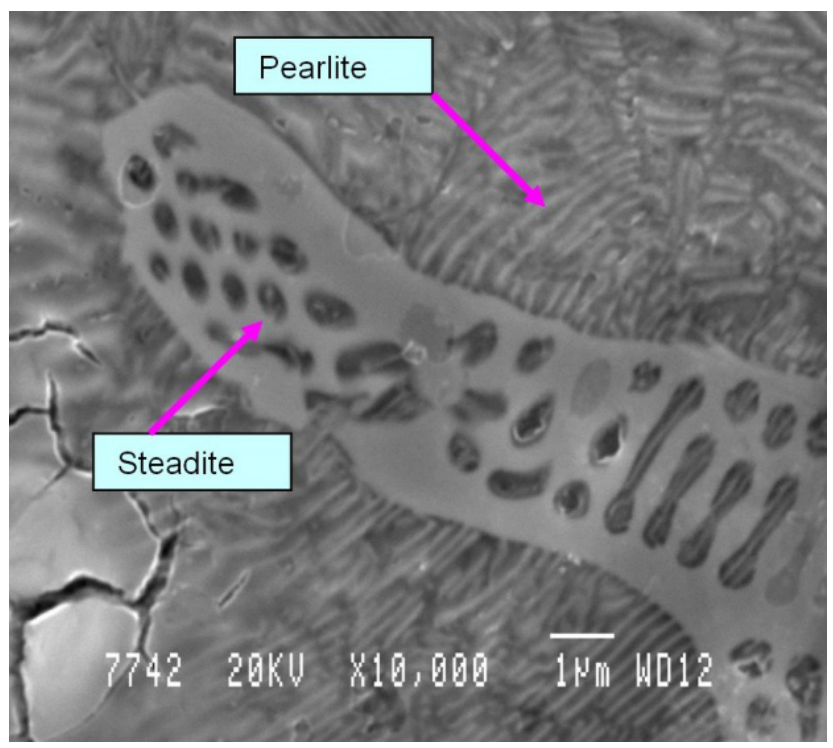

Figure 55. Steadite and Pearlite. 


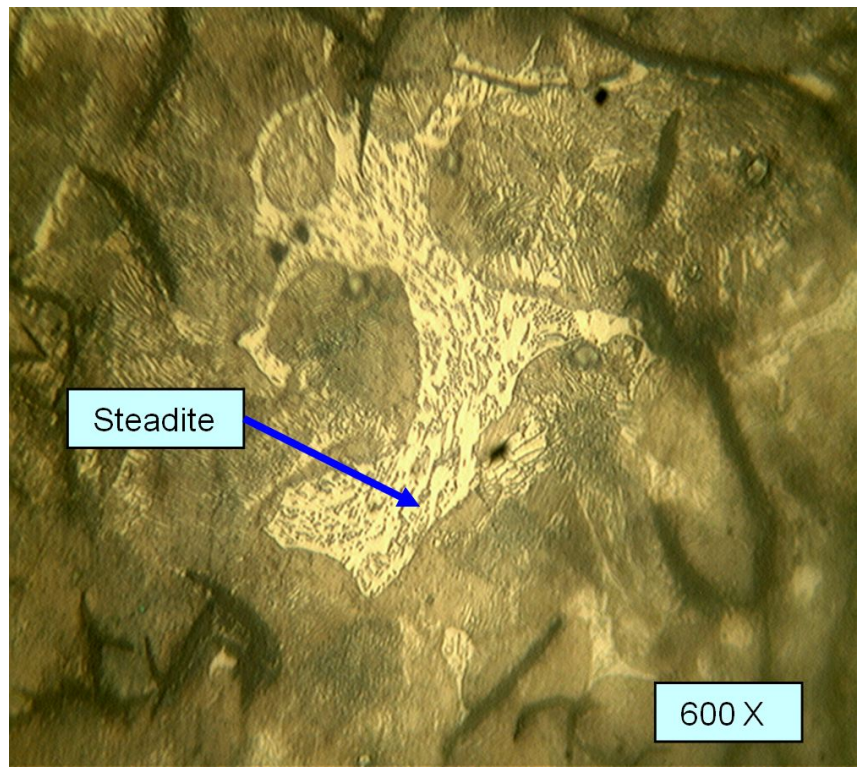

Figure 56. Steadite.

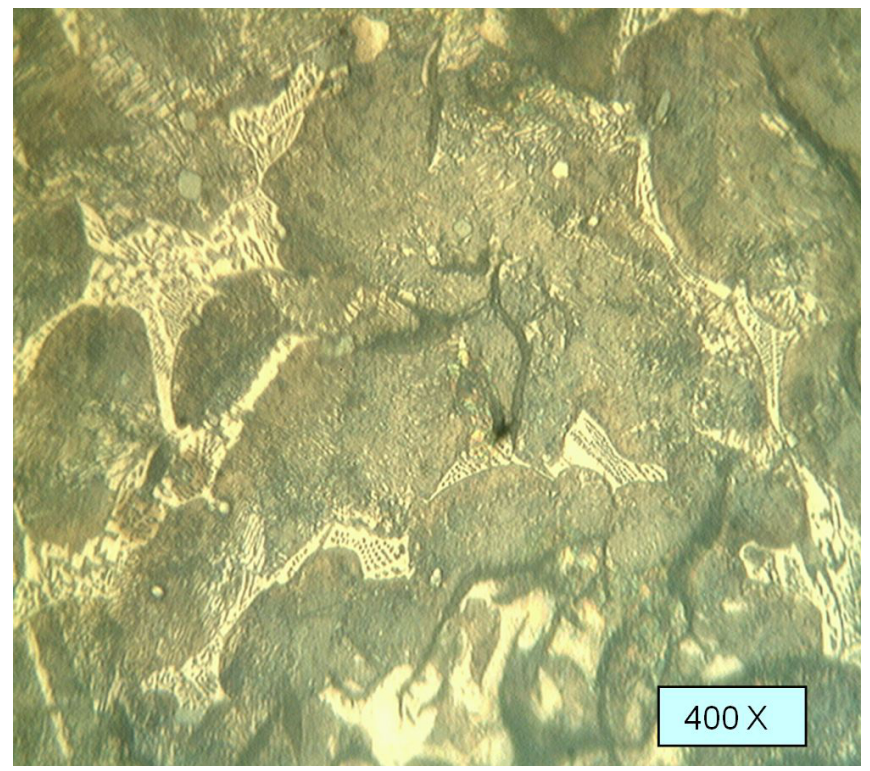

Figure 57. Steadite network. 


\section{Author details}

M. S. Ramaprasad ${ }^{1^{*}}$ and Malur N. Srinivasan ${ }^{2}$

*Address all correspondence to: vaidehi_ramaprasad_sk@yahoo.co.in

1 Foundry Consultant, Bangalore, India

2 Department of Mechanical Engineering, Lamar University, Beaumont, USA

\section{References}

[1] Technikon.LLC and Material Applications Branch of US Army Research laboratory (2004). Permanent Mold Technology. Document \# 1410 - 160Under CERP (Casting Emission Reduction Program), Oct.

[2] West, Charles. E., \& Grubach, Thomas. E. (1998). (Aluminum Company of America), Chapter on Permanent Mold casting, ASM Metals Hand Book, Volume 15 - CastingsFourth Printing, March.

[3] Teillet, Rafael. M. (1962). Permanent mold casting. Mod. Casting, 41, May, 103.

[4] Henzel, J. G. Jr., \& Kaverian, J. (1966). Gap Formation In Permanent Mold Castings. p. 373, Trans AFS.

[5] WTEC (2001). Panel Report on "Environmentally Benign Manufacturing" International Technology Research Institute (TRI- Loyola College,Baltimore, MD 21210,USA), April.

[6] Gigante, Gary. (2010). How Can We become a Practically Green Foundry Industry ? “- AFS Hoyt Memorial Lecture for 2010.

[7] U.S. Department of Energy (2002). Metal Casting Industry of the Future: 2002 Annual Report.

[8] “CERP Organic HAP Emission Measurements For Iron Foundries and Their Use in Development of an AFS HAP Guidance Document", Technikon \# 1412-317 NA, Under CERP (Casting Emission Reduction Program), Jan 2006 \& Aug 2007.

[9] "Second Verification of SIVL (Systems Integration and Validation Laboratory): Triboelectric Particulate Monitors- Monitor A", Technikon \# 1411- 234- A, Under CERP (Casting Emission Reduction Program), July 2005.

[10] "Energy Reduction Projects", Technikon \# 1411- 815, Under CERP (Casting Emission Reduction Program), September 2005.

[11] Holmgren, Mats., \& Naystrom, Peter. (2008). "The Green Foundry" presented at 68th World Foundry Congress, Chennai, India, Feb. 
[12] Clark, Antony P., \& Cast-Tec Ltd. Ontario. (1982). "A new Development in ferrous Permanent Mold Casting", Modern casting, June.

[13] Lerner, Yury S. (1996). "Another Approach to Iron Castings", p. 48, Modern Casting, November.

[14] Francis, J. L. (1965). "Gravity Die Casting of Cast Iron", Foundry trade Journal, Vol. 118, p. 443, Apr.

[15] Frye, George. (1968). Eaton Gray Iron Castings by Permanent Mold Process. Modern Casting, Vol. 54, p. 52, Oct.

[16] A quick picture of the Eaton Permanent Mold Process for producing gray iron castings. A booklet published by Eaton Corporation, Michigan, USA.

[17] Clark, D. (1968). "Permanent Mold Aluminium and gray iron Castings at Forest City Foundries" Modern Castings, p. 65, Oct.

[18] Patent granted to Walter S. Anderson for development of permanent mold for cast iron. (1925) Published in Metal Founding, Aug.

[19] McClelland, H. U. (1959). "Grey Iron Permanent Molding", Modern Casting, Vol. 35, p. 68 , Apr.

[20] Miske, Jack C. (1966). "Ferrous Die Casting" A report on work progress, p. 10, FOUNDRY, July.

[21] Miske, Jack C. (1966). "Ferrous Die Casting" A report on work progress, p. 190, FOUNDRY, Oct.

[22] Barto, R. L., Hurd, D. T., \& Stoltenberg, J. P. (1967). "The pressure Die casting of Iron and Steel" p. 181, Trans. AFS, Vol. 75.

[23] Hurd, D. T. (1967). "Ferrous Die Casting" A Continuing Report, p. 127, Foundry, Nov.

[24] Die Casting of Nodular Iron (1968). p. 137, Foundry, Aug.

[25] Bates, C. E. (1972). "Profit Potential in Permanent Mold Iron Castings" Foundry, Vol. 100, p. 49, Nov.

[26] Ferrous Die casting In Ireland (1973). Foundry, p.91, Nov.

[27] Lusniak Lech, Ludmila. (1973). "Casting Permanent Molds in Poland" p. 93, Foundry, October.

[28] Fisher, T. P. (1967). "The Technology of Gravity Die casting", A Text Book, published by George Newnes Ltd., First Edition.

[29] Skrocki, R. R., \& Wallace, J. F. (1968). "Permanent Molding of Iron and Steel Castings" p. 581, Trans AFS, Vol. 76. 
[30] Skrocki, R. R., \& Wallace, J. F. (1969). "Control of Structure and Properties of Irons cast in Permanent Molds" Part I, p. 296, Trans AFS, Vol. 77.

[31] Skrocki, R. R., \& Wallace, J. F. (1970). "Control of Structure and Properties of Irons cast in Permanent Molds" Part II, p. 239, Trans AFS, Vol. 78.

[32] Permanent Mold Casting (1970). p. 265, Metals Hand Book, Vol. 5, 8th Edition, published by ASM.

[33] Schoendorf, P. (1970). "First Annual Summary of recent literature on Permanent Mold Casting of Cast Iron" Giesserei, Vol. 57, p. 715, Oct.

[34] Ramesh, K. (1973). "Studies on Hyper Eutectic Cast Iron cast in Metallic Molds" M.Sc Thesis, Indian Institute of Science.

[35] Zuithof, A. J., et al. (1972). "The section sensitivity of cast iron permanent mold castings" Cast Metals Research Journal, p. 83, Issue 2, Vol. 8, June.

[36] Ramaprasad, M. S., \& Srinivasan, M. N. (1975). Permanent Molding of Cast Iron. Indian Foundry Journal, 21(6), 1-7.

[37] Ramaprasad, M. S. (1976). PhD thesis, Indian Institute of Science.

[38] Ramaprasad, M. S., \& Srinivasan, M. N. (1977). Eutectic Cell Structure in Permanent Molded Cast Iron. Castings (Australia), 23(9/10), 27-35.

[39] Ramaprasad, M. S., \& Srinivasan, M. N. (1977). Permanent Molding of Cast IronThermal Behaviour. The British Foundryman, 70(12), 359-364.

[40] Ramaprasad, M. S., \& Srinivasan, M. N. (1977). Studies on Structure and Strength of Permanent Molded Cast Iron. Proceedings of the Department of Atomic Energy Symposium on Structure- Property Correlations and Instrumental Techniques in Materials Research, Rourkela, 73-87.

[41] Ramaprasad, M. S., \& Srinivasan, M. N. (1977). "Graphite Morphology in Permanent Molded Cast Iron" Paper sent for presentation at the Seminar on Structural Modification in Cast Iron, TMS-AIME Fall Meeting, Chicago.

[42] Ramaprasad, M. S., Narendranath, C. S., \& Srinivasan, Malur N. (1983). Some Aspects of Grey and Spheroidal Graphite Iron Cast in Metallic Molds. Proceedings of the ISI Conference on "Solidification in the Foundry and Cast House, University of Warwick, U.K., The Metals Society, 336-344.

[43] Rassenfoss, J. A. (1977). "Mold Materials for Ferrous castings" AFS Hoyt Memorial Lecture for 1977.

[44] Gravity Diecasting of Iron- The Russel Cast-Tec Process (1984). p. 77, Foundry Trade Journal, Feb.

[45] Clark, A. P., \& Godsell, B. C. (1984). Answers to Questions about Ferrous Permanent Molding. p. 25, Modern Casting, Feb. 
[46] Elliott, Roy. (1988). Chapter on permanent Molding, Test Book "Cast Iron" Butterworth \& Co (Publishers) Ltd.

[47] Henych, I., \& Gysel, W. (1982). "Development of the high performance die as a basis for a mechanized permanent mold casting process for medium weight cast iron parts" paper presented at 49th International Foundry Congress, Chicago.

[48] Cast Tec Ltd., Ontario (1989). "Producing As-cast ferrous Permanent Mold castings" Modern casting, May, (special GIFA issue).

[49] Onyuna, M. O. (1994). Masters Degree Thesis, Dept. of Mechanical of Mechanical Engineering, University of Nairobi.

[50] Ramaprasd, M. S., Patel, Bhupendra C., Patel, Devendra B., Patel, Paresh B., Patel, Pradip B., \& Patel, Dilip M. (1977). "The Development of Cast Iron Permanent Molding Technology at Allparts castings Limited, and Experiences Gained" Presentation made as a participant of "UNIDO Innovation Technology Management Program", Nairobi. 